\title{
A chamber study of the influence of boreal BVOC emissions and sulfuric acid on nanoparticle formation rates at ambient concentrations
}

\author{
M. Dal Maso ${ }^{1}$, L. Liao ${ }^{2}$, J. Wildt ${ }^{4}$, A. Kiendler-Scharr ${ }^{3}$, E. Kleist ${ }^{4}$, R. Tillmann ${ }^{3}$, M. Sipilä ${ }^{2}$, J. Hakala ${ }^{2}$, \\ K. Lehtipalo ${ }^{2}$, M. Ehn ${ }^{2}$, V.-M. Kerminen ${ }^{2}$, M. Kulmala ${ }^{2}$, D. Worsnop ${ }^{2}$, and T. Mentel ${ }^{3}$ \\ ${ }^{1}$ Department of Physics, Tampere University of Technology, P.O. Box 692, 33100 Tampere, Finland \\ ${ }^{2}$ Department of Physics, University of Helsinki, P.O. Box 64, 00014, Helsinki, Finland \\ ${ }^{3}$ IEK-8, Forschungszentrum Jülich, 52425 Jülich, Germany \\ ${ }^{4}$ IBG-2, Forschungszentrum Jülich, 52425 Jülich, Germany
}

Correspondence to: M. Dal Maso (miikka.dalmaso@tut.fi)

Received: 8 October 2014 - Published in Atmos. Chem. Phys. Discuss.: 11 December 2014

Revised: 31 December 2015 - Accepted: 14 January 2016 - Published: 22 February 2016

\begin{abstract}
Aerosol formation from biogenic and anthropogenic precursor trace gases in continental background areas affects climate via altering the amount of available cloud condensation nuclei. Significant uncertainty still exists regarding the agents controlling the formation of aerosol nanoparticles. We have performed experiments in the Jülich plant-atmosphere simulation chamber with instrumentation for the detection of sulfuric acid and nanoparticles, and present the first simultaneous chamber observations of nanoparticles, sulfuric acid, and realistic levels and mixtures of biogenic volatile compounds (BVOCs). We present direct laboratory observations of nanoparticle formation from sulfuric acid and realistic BVOC precursor vapour mixtures performed at atmospherically relevant concentration levels. We directly measured particle formation rates separately from particle growth rates. From this, we established that in our experiments, the formation rate was proportional to the product of sulfuric acid and biogenic VOC emission strength. The formation rates were consistent with a mechanism in which nucleating BVOC oxidation products are rapidly formed and activate with sulfuric acid. The growth rate of nanoparticles immediately after birth was best correlated with estimated products resulting from $\mathrm{BVOC}$ ozonolysis.
\end{abstract}

\section{Introduction}

Studies in ambient environments have identified several strong candidates to act as the responsible agents for nanoparticle formation, the strongest being the sulfuric acid molecule, $\mathrm{H}_{2} \mathrm{SO}_{4}$ (Weber et al., 1996; Sipila et al., 2010; Kuang et al., 2008). Climate and other effects of atmospheric aerosols are tied strongly with their concentrations, and, in that way, on aerosol sources. Current experimental and theoretical understanding of nanoparticle formation suggests that in addition to $\mathrm{H}_{2} \mathrm{SO}_{4}$, other compounds are needed to stabilise the initial clusters of sulfuric acid to initiate new particle formation (Ball et al., 1999; Zhang et al., 2004; Murphy et al., 2007). Recent experimental and theoretical evidence has shown that basic gases, e.g. ammonia or certain amines could act as such stabilizing agents (Almeida et al., 2013; Smith et al., 2010; Berndt et al., 2010).

In addition to these bases, various organic compounds have been proposed to participate in the particle formation process (Zhang et al., 2004; Paasonen et al., 2010; Metzger et al., 2010; O’Dowd et al., 2002). Several laboratory studies have shown evidence of biogenically emitted volatile organic compounds (BVOCs) acting as precursors for aerosol number formation (Schobesberger et al., 2013; Ehn et al., 2014; Mentel et al., 2009; Hao et al., 2009; Joutsensaari et al., 2005). Particle formation has been shown to correlate positively with the amount of precursor BVOCs, but also to depend strongly on the composition of emitted BVOC mixture 
(Mentel et al., 2009; Kiendler-Scharr et al., 2009). It has been shown that vegetation stress conditions clearly influence the amount of secondary aerosol formed from oxidizing plant emissions in addition to model compound studies (Mentel et al., 2013).

Despite the strong evidence of plant-emitted BVOC influencing the formation process of new particles, there are still significant uncertainties on the identity of the BVOC that actually cause nucleation, as it has been shown before that the mixture of BVOC can play a significant role in particle formation; for example, alpha-pinene is a weaker precursor for nucleation than realistic boreal plant emission mixtures (e.g. Mentel et al., 2009); on the other hand, certain BVOC can inhibit particle formation (Kiendler-Scharr et al., 2009). Detailed, formation-specific measurements with quantification of sulfuric acid and realistic BVOC mixture emissions at concentration levels corresponding to the natural atmosphere are currently still lacking. In this study, we performed such measurements to elucidate the role of plant BVOC oxidation and sulfuric acid in atmospheric aerosol formation.

Using the capability of the Particle Size Magnifier (PSM Vanhanen et al., 2011) to observe particles at their original sizes, we performed a set of experiments at the Jülich plantatmosphere chamber (see set-up Mentel et al., 2009). Emissions from a group of small trees, representative of the boreal forest species, were introduced to a reaction chamber and underwent oxidation with $\mathrm{O}_{3}$ and $\mathrm{OH}$. Simultaneous photochemical production of $\mathrm{H}_{2} \mathrm{SO}_{4}$ took place in the reaction chamber. Sulfuric acid levels in the experiment corresponded to levels observed in the atmosphere (Paasonen et al., 2010; Hamed et al., 2007, 2010) and the BVOC emissions were also similar to actual continental boreal forest background values. In this paper, we will give an overview of the data set obtained in our measurements, and present the results of the particle formation and growth rate analysis together with a discussion of the particle formation mechanism that could lead to our observations. The experiment is, to our knowledge, the first experimental series in which realistic BVOC mixtures (in terms of both concentration levels and composition) have been measured together with realistic $\mathrm{H}_{2} \mathrm{SO}_{4}$ concentrations. As the data set presents an excellent opportunity to test the performance of the aerosol dynamics process model MALTE (Boy et al., 2006), we have also simulated the data set using the aforementioned model; the results of the detailed aerosol dynamics and gas phase chemistry simulations will be presented in a companion paper (Roldin et al., 2015). In this paper, our aim is to test the hypotheses that (a) BVOCs contribute to the nanosized condensation nuclei (nanoCN) formation process itself, (b) that sulfuric acid is participating in the formation process, and that (c) organic oxidation compounds are critical for the growth of small particles. In addition, our aim is to discuss our findings with respect to the possible gas-phase reactions leading to compounds participating in particle formation, and the role of boreal forest BVOC emissions in realistic concentrations.

\section{Materials and methods}

\subsection{The JPAC chamber set-up}

A detailed description of the chamber set-up used for these experiments (Jülich Plant Atmosphere Chamber facility, JPAC) and its performance is given in Mentel et al. (2009). In short, the facility consisted of two borosilicate glass chambers (Volumes 1150 and $1450 \mathrm{~L}$ ) with Teflon floors. Each chamber was mounted in separate climate controlled housing separately adjustable to temperatures between 10 and $50^{\circ} \mathrm{C}$. Discharge lamps (HQI $400 \mathrm{~W} / \mathrm{D}$; Osram, Munich, Germany) were used to simulate the solar light spectrum. At full illumination and at typical mid-canopy heights, photosynthetic photon flux density (PPFD) was $480 \mu \mathrm{mol} \mathrm{m}^{-2} \mathrm{~s}^{-1}$ in the $1150 \mathrm{~L}$ chamber. During the experiments described here PPFD in the $1450 \mathrm{~L}$ chamber was $60 \mu \mathrm{mol} \mathrm{m}^{-2} \mathrm{~s}^{-1}$. The smaller chamber was used as plant chamber, and the larger chamber was used as reaction chamber. A schematic of the plant chamber set-up is given in Fig. 1. The general operation of the plant chamber was similar to the procedures described in Mentel et al. (2009). Cleaned air was pumped through the plant chamber and a fraction of the air leaving the plant chamber $\left(\approx 20 \mathrm{~L} \mathrm{~min}^{-1}\right)$ was fed into the reaction chamber. Besides the inlet for the air from the plant chamber, the reaction chamber had another separate inlet to add ozone and to allow keeping the humidity in the reaction chamber constant. Altogether, the flow into the reaction chamber was ca. $30 \mathrm{~L} \mathrm{~min}^{-1}$ on average; the outflow of the chamber was equal to the sum of the inflow, and the chamber was kept at a small overpressure to avoid outside contamination. Due to the additional dilution caused by the ozone and humidification flow, the BVOC concentration of the reaction chamber with no ongoing oxidation was ca. $60-70 \%$ of the plant chamber concentration. The conditions in the reaction chamber were held constant for all experiments $\left(T=15 \pm 0.5^{\circ} \mathrm{C}\right.$, $\mathrm{rH}=62 \pm 2 \%,\left[\mathrm{O}_{3}\right]=60-70 \mathrm{ppb}$ without UV light and 30 to $35 \mathrm{ppb}$ with UV light). $\mathrm{OH}$ radicals were generated by ozone photolysis (a UV lamp, Philips, TUV $40 \mathrm{~W}, \lambda_{\max }=254 \mathrm{~nm}$, $J\left(\mathrm{O}^{1} \mathrm{D}\right) \approx 2.910^{-3} \mathrm{~s}^{-1}$, situated inside the reaction chamber) and subsequent reaction of $\mathrm{O}^{1} \mathrm{D}$ with water. Threeto four-year-old tree seedlings brought from Hyytiälä were used to study SOA formation. Species used were Norwegian spruce (Picea abies L.) Scots pine (Pinus sylvestris L.), and Silver birch (Betula pendula L.) (one of each species). Before the measurements the plants were stored outside near to a forest to obtain realistic conditions with all the environmental impacts plants experience in their environment. After that the trees were introduced in the plant chamber and allowed to adapt to the chamber for several days. While the conditions in the reaction chamber were held strictly constant, those in the plant chamber were varied from experiment to experiment. Changing temperature and PPFD in the plant chamber caused changes of the emission strengths and thus changes of the source strengths for the reactants in the reaction chamber. 


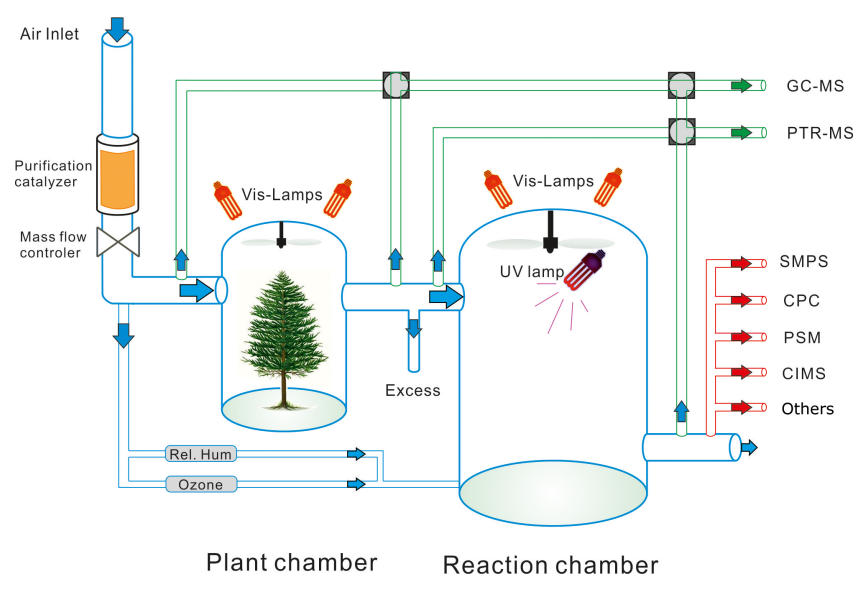

Figure 1. A schematic illustration of the Jülich Plant Chamber (JPAC) set-up as it was during the experiments presented here.

This procedure allowed determining the impact of the BVOC load on nucleation of nanoparticles. Generation of $\mathrm{OH}$ radicals was performed when the BVOC concentrations in the reaction chamber were near to steady state. New particle formation was induced only when there were no particles observable from the preceding experiment $\left(<100 \mathrm{~cm}^{-3}\right)$. As particles were still observable on time scales longer than half a day after the $\mathrm{OH}$ production was switched off, we induced particle formation about once a day. Seven to eight hours before switching on the UV light, the conditions in the plant chamber were changed, allowing a new steady state to be reached in the reaction chamber for the next experiment. $\mathrm{OH}$ radical induced particle formation was measured by a suite of instruments following the particles from sizes of 1 up to $600 \mathrm{~nm}$.

\subsection{Measurements}

The aim of the measurements was to quantify the rate of particle formation during $\mathrm{OH}$-induced oxidation while varying the amount of BVOC introduced into the reaction volume, and to simultaneously observe the variation of sulfuric acid concentrations. The set-up for characterizing the formation experiments is described in the following sections.

\subsubsection{CIMS}

Sulfuric acid was measured with self-built a chemical ionization mass spectrometer, CIMS (Petäjä et al., 2009; Mauldin et al., 1998). In the measurement, the sulfuric acid is chemically ionized by $\left(\mathrm{NO}_{3}^{-}\right)$ions in the sample flow. The reagent ions are generated by a ${ }^{241} \mathrm{Am}$ alpha source and nitric acid, and then mixed in a controlled manner in a drift tube with concentric sheath and sample flows together with electrostatic lenses. Then, the chemically ionized sulfuric acid molecules pass through a layer of dry nitrogen flow in order to dehydrate the sulfuric acid prior to entering the vacuum system. Once in the vacuum system, the sulfuric acid clusters are dissociated from the core ions by collisions with nitrogen gas seeping through the pinhole in the collision-dissociation chamber. The sample beam, collimated with a set of conical octopoles, is detected with a channeltron after mass filtration with a quadrupole. The sulfuric acid concentration is determined by the ratio between the signals at mass $97 \mathrm{amu}$ $\left(\mathrm{HSO}_{4}^{-}\right)$and the reagent ion at mass $62 \mathrm{amu}\left(\mathrm{NO}_{3}^{-}\right)$multiplied by the instrument and set-up dependent calibration factor. The instrument used in this study was the same as that used in the studies by Sipila et al. (2010). The nominal detection limit of the CIMS is $5 \times 10^{4} \mathrm{~cm}^{-3}$ over a 5 min integration period. The error estimate in the observed concentrations is given as factor of 2. Additionally, losses in the sampling line cause additional uncertainty in our measurement. However, these uncertainties represent a constant factor in the absolute values observed, whereas our analysis depends on relative changes in the observed concentration. Therefore, whenever shown, we show the part of uncertainty representing random error in our plots, estimated as the short-term standard deviation after de-trending the measurement. When comparing to other observations, the instrument specific uncertainty is cancelled out by the fact that most other sulfuric acid observations available in literature are obtained using similar instrumentation (Paasonen et al., 2010) or even the same instrument (Sipila et al., 2010; Petäjä et al., 2009).

\subsubsection{VOC measurements}

The concentrations of plant-emitted volatile organic compounds were determined by proton transfer reaction mass spectrometry (PTR-MS, Ionicon) and by a gas chromatography mass spectrometer (described in Heiden et al., 2003). The PTR-MS measurements were performed with a time resolution of $10 \mathrm{~min}$, and the PTR-MS was switched between the outlet line of the plant chamber and the outlet line of the reaction chamber. The reactant source rate to the reaction chamber was deduced by accounting for the dilution factor caused by ozone and water vapour addition to the plant chamber outflow (Mentel et al., 2009). The GC-MS system was optimized to measure BVOC from $\mathrm{C}_{5}$ to $\mathrm{C}_{20}$. It was used to identify individual BVOC and to quantify its concentrations at the outlet of the plant chamber. Another GC-MS system was used to quantify $\mathrm{OH}$ concentrations by determining the decrease in concentration of a tracer compound in the reaction chamber (Kiendler-Scharr et al., 2009). Calibration of all systems was conducted as described in Heiden et al. (2003). 


\subsubsection{Aerosol measurements}

The physical characterization of aerosol populations was performed with a set of instruments, with the aim of very detailed characterization of the nanoCN formation size range and to obtain particle formation rates independent of the growth rate. A TSI Scanning Mobility Particle Sizer (SMPS TSI3071+TSI3025A) was used to measure the particle size distribution in the size range $15-600 \mathrm{~nm}$. We used a TSI condensation particle counter (CPC TSI3022A) with a lower detection size limit of $7 \mathrm{~nm}$ to measure the total number of particles larger than $7 \mathrm{~nm}$. To detect the smallest particles, we used a Particle Size Magnifier (PSM, Airmodus A09 prototype) to lower the cut-off size of a TSI CPC TSI3022A. In the PSM the aerosol is turbulently mixed with air saturated with diethylene glycol, therefore creating a supersaturation high enough to activate even $1 \mathrm{~nm}$ ions, the nominal cut-off size being about $1.6 \mathrm{~nm}$. The PSM was situated next to the reaction chamber, inside the thermal insulation, to minimize tube losses. The sampling line length was approximately $1 \mathrm{~m}$.

\subsection{Experimental overview}

During the experimental campaign, we performed a VOC and $\mathrm{SO}_{2}$ oxidation experiment roughly once every day. Aiming for atmospheric concentrations of VOC and sulfuric acid, we gradually reduced BVOC concentrations by reducing the temperature in the plant chamber; by varying the amount of $\mathrm{OH}$ generated we reduced the sulfuric acid production rate. For a given $\mathrm{OH}$ source strength, determined by the UV flux (controlled by opening of UV shielding of the reaction chamber UV light, see Sect. 2.1), $\mathrm{O}_{3}$ and water concentration in the reaction chamber, the $\mathrm{OH}$ level is to a large extent determined by the amount of $\mathrm{OH}$-reactive $\mathrm{VOC}$ available in the chamber. The sulfuric acid concentrations observed were ca. (3-4) $\times 10^{5} \mathrm{~cm}^{-3}$ in non-oxidizing periods (UV light off). During $\mathrm{OH}$ production, the observed concentrations were between $1.5 \times 10^{6}$ and $1.0 \times 10^{7} \mathrm{~cm}^{-3}$. The lowest concentrations were obtained during an experiment in which no ozone was added to the reaction chamber (the afternoon of 23 September). This was due to the production mechanism of $\mathrm{OH}$, which depends on the $\mathrm{O}_{3}$ concentration. Depending on the conditions in the reaction chamber, $\mathrm{OH}$ concentrations deduced from GC-MS measurements were in the range between $10^{7}$ and $10^{8} \mathrm{~cm}^{-3}$. The $\mathrm{SO}_{2}$ needed for sulfuric acid production originated as a low background value in the purified air. An overview of the particle size distributions, sulfuric acid and particle concentrations, and BVOC concentrations in the plant chamber and the reaction chamber can be seen in Fig. 2. In addition to the data shown, we also performed experiments with pure alpha-pinene on the 27 September, and zero experiments (no BVOC added to the chamber) on 26 September and 1 October (with added $\mathrm{SO}_{2}$ ).

\subsubsection{PSM detection size in relation to the particle formation size}

A key factor in our experiment was our ability to detect freshly formed aerosol particles very shortly after they had been formed, and before they had grown significantly. In the following, we will present the justification that this assumption was indeed correct. When the UV light was switched off in the chamber, the nanoparticle concentration observed by the PSM was approx. $100-200 \mathrm{~cm}^{-3}$. When applying a HEPA filter to the inlet line, the instrument showed 1015 counts $\mathrm{cm}^{-3}$. This is in line with the small amount of sulfuric acid present in the chamber at this time, and also proves that no significant contribution from nucleation inside the instrument was present. Upon igniting the UV light, the particle concentration seen by the PSM started to increase almost immediately, as did the sulfuric acid concentration (see Fig. 3). We consider the short time difference between the start of $\mathrm{OH}$ production and increase in the concentration measured by the PSM as proof of measuring nanoparticles at the size at which they are formed. We have tabulated the time that elapsed from the moment of UV ignition to the time that the PSM concentration reading reached a multiple of 2 and 5 of the "dark" concentration in Table 1 . If we now consider the case of the highest growth rates of the 1.6-7 nm particles, (ca. $90 \mathrm{~nm} \mathrm{~h}^{-1}$, see Sect. 3.2) and factor in a $\Delta t$ of $16 \mathrm{~s}$ to doubling the particle concentration, we get at maximum a $0.4 \mathrm{~nm}$ difference between the detection limit of the PSM and the formation size of particles. This is likely an overestimation, since the rise in concentration can be clearly recognized earlier than the $16 \mathrm{~s}$ used. One must also assume a timescale for the nucleation process itself, as well as a transport time from inside the chamber to the instrument. (The nucleation process gives a timespan of ca. $10 \mathrm{~s}$ for doubling the concentration of $150 \mathrm{~cm}^{-3}$, applying the maximum nucleation rate of $15 \mathrm{~cm}^{-3} \mathrm{~s}^{-1}$.) Taking this all into account, we realistically expect to detect particles only $0.05-0.1 \mathrm{~nm}$ larger than the actual formation size.

\subsection{Obtaining particle formation rates}

A fresh nanoparticle of a size range $\left[d_{\mathrm{p}}, d_{\mathrm{p}}+\Delta d_{\mathrm{p}}\right]$ formed in the reaction chamber can have the following fates during its lifetime: (i) it grows to a larger size (ii) it coagulates with other particles (iii) it is lost to chamber walls (iv) it is flushed out of the chamber into the sampling line. Therefore, for the particle concentration $N_{i}$ in our size range, we can write for its change in time

$\frac{\mathrm{d} N_{i}}{\mathrm{~d} t}=J_{i}-C_{i} N_{i}-N_{i} \sum_{j} K_{i j} N_{j}-\omega_{i} N_{i}-\gamma N_{i}$.

Herein, $J_{i}$ is the formation rate of particles in the size range, $\omega$ is a size-dependent wall-loss parameter, $C_{i}$ is the growth rate out of the size range (defined as $C_{i}=$ $1 / \Delta d_{\mathrm{p}}$. GR, with GR as the diameter growth rate $\mathrm{d} d_{\mathrm{p}} / \mathrm{d} t$; see 

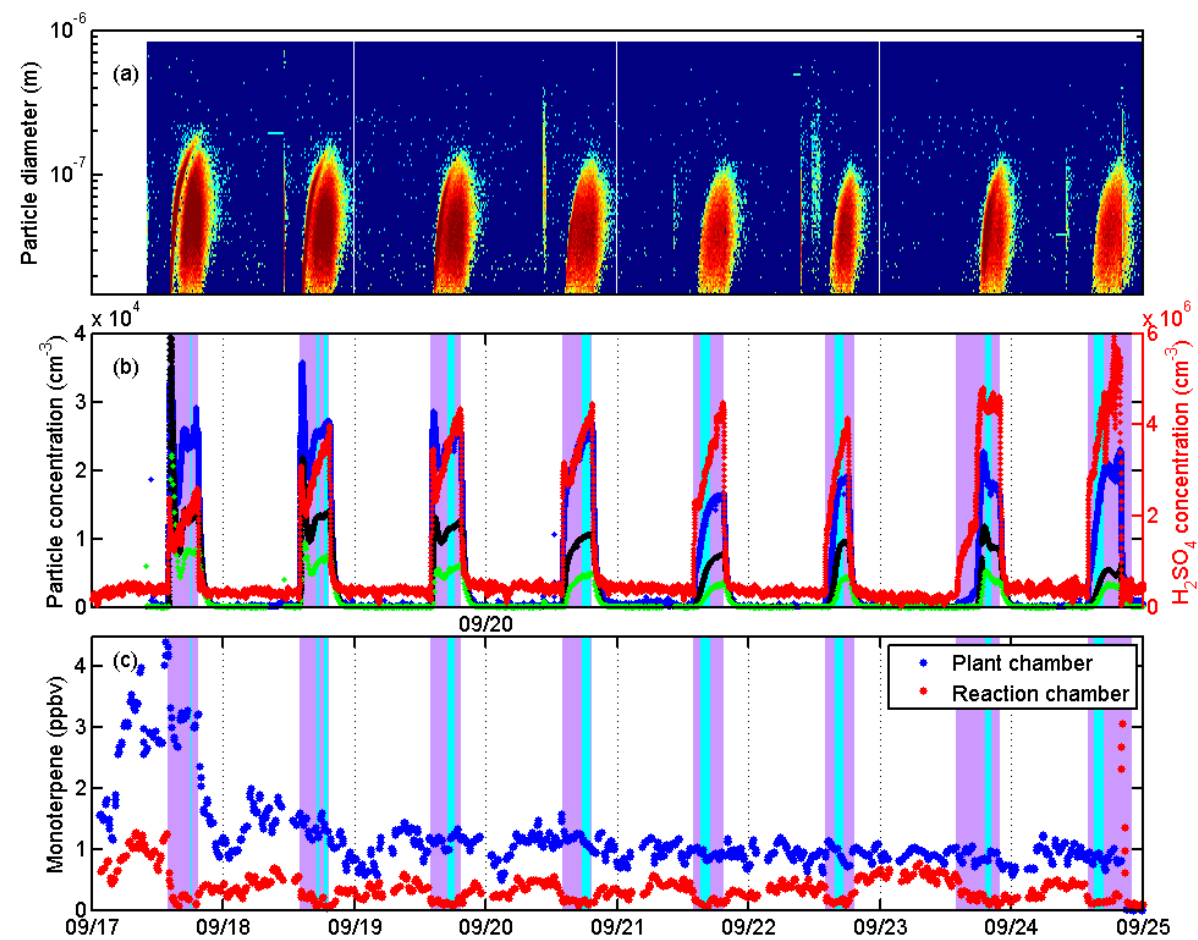

Figure 2. (a) Contour plots of aerosol particle number size distributions as function of time measured by SMPS. (b) Time series of total particle number concentrations (blue: PSM concentration, black: CPC concentration, green: SMPS concentration) and sulfuric acid concentrations (red), and (c) time series of monoterpene concentrations measured by PTR-MS during the chamber experiments for both chambers. The purple bars indicate the UV-on periods and the cyan bars illustrate the selected periods of steady state for calculating nanoCN formation rates (see Sect. 2.4). On 23 September, the event starting later is due to late ozone addition.

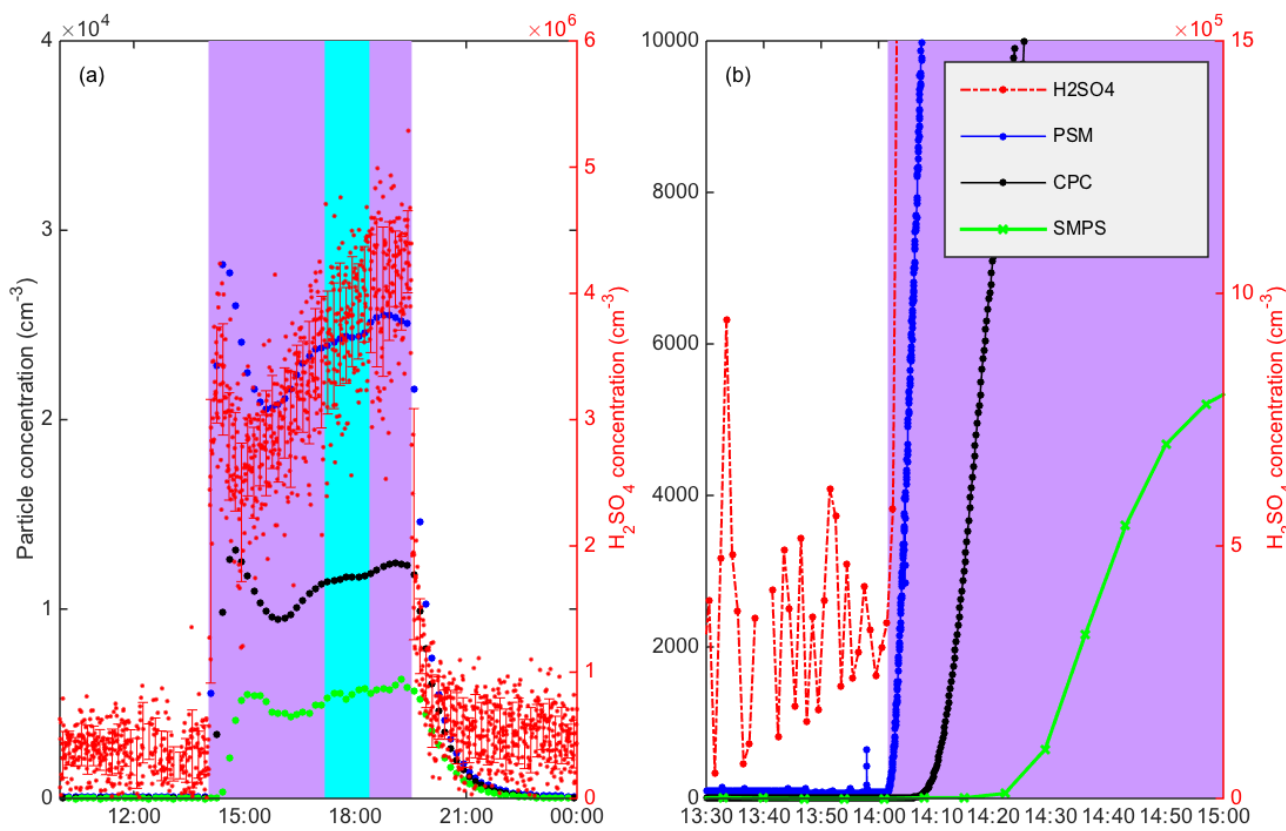

Figure 3. (a) A time series of PSM (blue markers), CPC (black), and CIMS (red) data at the start of one event. The purple area illustrates the time period that UV light was switched on in the reaction chamber. The area shaded blue is the steady-state period from which the particle formation rate was obtained. Sub-figure (b) shows the zoomed-in time delay of particle formation after turning the UV light on, which was used to verify that particles are measured very close to their formation sizes. 
Table 1. Overview of the particle formation experiments performed, as well as the time delay between lighting the UV light and observing a concentration increase, measured by the PSM instrument.

\begin{tabular}{lrrrl}
\hline Event & $\Delta t_{x 2}(\mathrm{~s})$ & $\Delta t_{x 5}(\mathrm{~s})$ & $\Delta t_{x 10}(\mathrm{~s})$ & Notes \\
\hline 18 Sep 14:01:36 & 16 & 48 & 76 & Plant experiment \\
19 Sep 14:01:36 & 23 & 48 & 76 & Plant experiment \\
20 Sep 14:01:36 & 24 & 59 & 92 & Plant experiment \\
21 Sep 14:01:36 & 25 & 69 & 106 & Plant experiment \\
22 Sep 14:01:36 & 40 & 101 & 137 & Plant experiment \\
23 Sep 14:01:36 & 128 & - & - & No ozone \\
24 Sep 14:01:36 & 31 & 81 & 137 & Plant experiment \\
26 Sep 13:01:21 & 117 & 226 & - & Zero experiment \\
27 Sep 13:01:21 & 135 & - & - & $\alpha$-pinene experiment \\
\hline
\end{tabular}

The subscript for $\Delta t$ states the value that the PSM concentration has reached in time $\Delta t$, with respect to the value at $\mathrm{UV}$ on $(t=0)$. E.g. $\Delta t_{x 2}=16 \mathrm{~s}$ means that the concentration doubled in $16 \mathrm{~s}$.

Dal Maso et al. (2002, e.g.)), $K_{i j}$ is the coagulation coefficient between particles in size ranges $i$ and $j$ and $\gamma$ is the flush out. For the next-largest size range, $N_{i+1}, J_{i+1}$ is equal to $C_{i} N_{i}$. Therefore, for sequential size ranges, we can write the following:

$$
\begin{aligned}
\frac{\mathrm{d} N_{1}}{\mathrm{~d} t} & =J_{1}-J_{2}-N_{1} \sum_{j} K_{1 j} N_{j}-\omega_{1} N_{1}-\gamma N_{1} \\
\frac{\mathrm{d} N_{2}}{\mathrm{~d} t} & =J_{2}-J_{3}-N_{2} \sum_{j} K_{2 j} N_{j}-\omega_{2} N_{2}-\gamma N_{2} \\
& \vdots \\
\frac{\mathrm{d} N_{n}}{\mathrm{~d} t} & =J_{n}-J_{n+1}-N_{n} \sum_{j} K_{n j} N_{j}-\omega_{n} N_{n}-\gamma N_{n} .
\end{aligned}
$$

We now assume that for the largest size range, the growth out of the largest size range is negligible, and thus $J_{n+1}$ is 0 . Knowing the concentrations $N_{i}$, and their time derivatives, we can now solve for $J_{1}$ and arrive at

$$
J_{1}=\sum_{i=1}^{n} \frac{\mathrm{d} N_{n}}{\mathrm{~d} t}+\sum_{i=1}^{n}\left(\sum_{j} K_{n j} N_{j}+\omega_{i}+\gamma\right) N_{i} .
$$

The coagulation coefficient was calculated using the Fuchs flux matching theory and the dilution (flushout) was taken from measured chamber flow rates. We now assume that the rate of formation at the detection limit of the PSM, measuring the smallest particles, was our formation rate of nanoparticles. The size ranges that we used for analysis were based on the instrumentation available: $N_{1.6-7 \mathrm{~nm}}, N_{7-15 \mathrm{~nm}}$, and $N_{>15 \mathrm{~nm}}$. These correspond to concentrations measured with different instruments: $N_{1.6-7 \mathrm{~nm}}=N_{\mathrm{PSM}}-N_{\mathrm{CPC}}, N_{7-15 \mathrm{~nm}}=$ $N_{\mathrm{CPC}}-N_{\mathrm{SMPS}}$, and $N_{>15 \mathrm{~nm}}=N_{\mathrm{SMPS}}$, the concentrations referring to the total concentrations measured by the instruments indicated by the subscripts. The benefit of this approach is the fact that no measurement-based estimate of the growth rate is required. Therefore, we can obtain a formation rate independently from the growth rate. However, the relatively broad size channels carry the possibility of causing errors to the estimation of $J$, because the size distribution inside the channels is not known. This is, however, mitigated by our choice of slow-changing size distributions (closed state to steady state). The parameters $\Sigma_{j} K_{i j} N_{j}$ and $\omega_{i}$ are sizedependent; however, instead of knowing the exact size distribution inside the size channels, it is equivalent to find the size of particles inside the size channel that would lead to the same coagulation loss rate $N_{i} \Sigma_{j} K_{i j} N_{j}$ if all particles in the size class $i$ were replaced by particles of this specific size. This is conceptually similar to finding the condensation sink diameter (CoSD, Lehtinen et al., 2003) for the size interval, but instead for the coagulation sink. Using observed concentration observations and fits using 1 st and 2 nd order polynomials, we found that the CoSD varied very little for the smallest size class, being $3.0 \pm 0.1 \mathrm{~nm}$. A $0.1 \mathrm{~nm}$ error in the estimation of the CoSD inside the size class causes an error in the coagulation loss rate of ca. $5 \%$; therefore, we estimate that the error in our coagulation losses, and also $J_{d^{*}}$, were approximately $20 \%$. For larger particles, the size distribution becomes less steep, and also the coagulation rate is less sensitive on the particle diameter; therefore, the error in larger sizes is likely to be minimal compared to instrument precision. On 23 September in the afternoon, we performed an experiment in which the $\mathrm{O}_{3}$ supply was turned off for the afternoon, and the chamber was illuminated with the UV light. This lead to a low formation rate of particles, but most crucially, also the growth rate of particles was very low, and practically no particles reached the detection size of the CPC. Therefore, we did not apply the aforementioned method for this period, but instead simply used the time differential of the PSM data corrected with losses to obtain the formation rate. These points are indicated separately in the results. After the ozone supply was turned on, we observed a normal particle formation event (see Fig. 2). Wall losses were empirically assessed in experiments from the concentration fall-off after the UV was turned off; for the smallest size range, the wall losses were estimated to be $5 \times 10^{-4} \mathrm{~s}^{-1}$, 
which is of the order of the dilution rate. For larger particles, the wall-loss coefficient was estimated from the wall-loss coefficient for the smallest particles, and by assuming that it is proportional to the particle diffusion coefficient, Verheggen and Mozurkewich (following 2006).

\subsection{Obtaining particle growth rates}

At the start of a particle formation pulse, one can obtain the particle growth rates following the time delays in the rise of the particle concentration of PSM, CPC, and SMPS, similarly to the analysis to determining the detection size of the PSM. We used the size sections 1.6-7 nm (PSM-CPC) and $7-15 \mathrm{~nm}$ (CPC-SMPS), which again correspond to the detection limits of the instruments used. The growth rate was obtained by dividing the difference of the size cut-off diameter of each instrument with the time difference of observing $N_{0.5 \times \max }$, the concentration that was $50 \%$ of the maximum concentration observed for each respective instrument. This is also the time of the maximum time differential in the concentration of each instrument, which can be interpreted as the peak of a log-normal fresh mode passing the detection limit. Therefore, this method gives us the change in time of the count mean diameter of the fresh particle population, which is the conventional parameter used to represent growth rates of fresh particle population (see e.g. Leppä et al., 2011)

\section{Results and discussion}

In the following sections, we will show the results of the particle formation experiments, show the relation between the observed particle formation rates, sulfuric acid, and plantemitted VOC concentrations, discuss the particle growth rates, and discuss the possible particle formation mechanisms that could explain the observed correlations.

\subsection{Particle formation rates related to sulfuric acid and VOC emissions}

During periods when no UV light was on in the reaction chamber, PSM concentrations were of the order of a few hundreds of particles per $\mathrm{cm}^{3}$. This indicates that in our chamber, the formation rate of particles by ozonolysis is at maximum of the order of $0.1\left(\mathrm{~cm}^{3} \mathrm{~s}\right)^{-1}$ based on a steady-state analysis with dilution as the only sink. Additionally, it should be noted that because ozonolysis reactions of some BVOC (e.g. alphapinene) yield $\mathrm{OH}$ as a by-product, the formed particles may be produced by the $\mathrm{OH}$-reactions, and ozonolysis does not participate in particle production. These particles never grew to sizes where they could be observed by the CPC at $7 \mathrm{~nm}$. Based on this observation, we can state that BVOC ozonolysis alone cannot be responsible for observed atmospheric particle formation.

Clearly detectable particle formation was observed when the UV light was turned on. To derive the nanoCN formation rates at the PSM detection limit, we applied the data analysis methods described in Sect. 2.4 to the measured particle number concentration and size distribution data. This resulted in a time series of particle formation rates covering the whole particle formation event period. As the method relies on the assumption of a quasi-steady-state in the particle size distribution, we selected time periods during which changes in the particle concentrations, the size distribution, and BVOC observations were slow (see Fig. 2) for the formation rate analysis. We found that during a single event, after the initial burst of particles, sulfuric acid concentrations slowly increased as time progressed; simultaneously, also particle formation rates increased proportionally to the $\mathrm{H}_{2} \mathrm{SO}_{4}$ concentration. However, when conditions in the plant chamber were adjusted to change the VOC emission rates, the rate of formation for similar $\mathrm{H}_{2} \mathrm{SO}_{4}$ concentrations markedly changed (see Fig. 4).

A decrease in VOC inflow into the reaction chamber corresponded to a decrease in nanoCN formation rates. This was in line with existing hypotheses that compounds formed by the oxidation of plant-emitted VOCs are key compounds in the formation of new particles. Our data set contained two experiments in which we modulated the input into the reaction chamber: on 23 September, we turned off the ozone input to the chamber and turned the UV light on, and on 27 September, we replaced the plant chamber inflow with pure alphapinene. These days are indicated separately in Fig. 4, as the data analysis for those days was different than for the rest of the data. For the no-ozone experiment, sulfuric acid levels were very low $\left((1-2) \times 10^{6} \mathrm{~cm}^{-3}\right)$, and the nanoCN formation rate was also markedly lower than on the other days; the BVOC inflow into the chamber was on a level similar to that of the previous days, but the steady-state BVOC concentration was markedly higher both for the dark period and the UV-on period, in line with the removal of the ozonolysis reaction pathway and the reduction of $\mathrm{OH}$ production from ozone photolysis. The nanoCN formation rate calculation for this experiment was based only on PSM data, as described in Sect. 2.4. For the alpha-pinene experiment, we had no direct measurement of the BVOC source rate, as the plant chamber was bypassed; however, we can estimate the source rate from the dark-time steady state concentration in the reaction chamber. The concentration was similar to the concentration at the highest plant-induced event, corresponding to an plant chamber concentration of 3-4 ppb. However, the particle formation rate was very much lower than during the plant-induced events (Fig. 2) despite the sulfuric acid level being at a similar level to the strongest of those events. This makes the alpha-pinene event a clear outlier of our data, and it has been excluded from the following correlation analysis.

Following the methodology of earlier studies (e.g. Paasonen et al., 2010), we attempted to relate the observed particle formation rate to the product of $\mathrm{BVOC}$ and oxidants $\left(\mathrm{O}_{3}\right.$ and $\mathrm{OH})$, and sulfuric acid in the reaction chamber, correspond- 

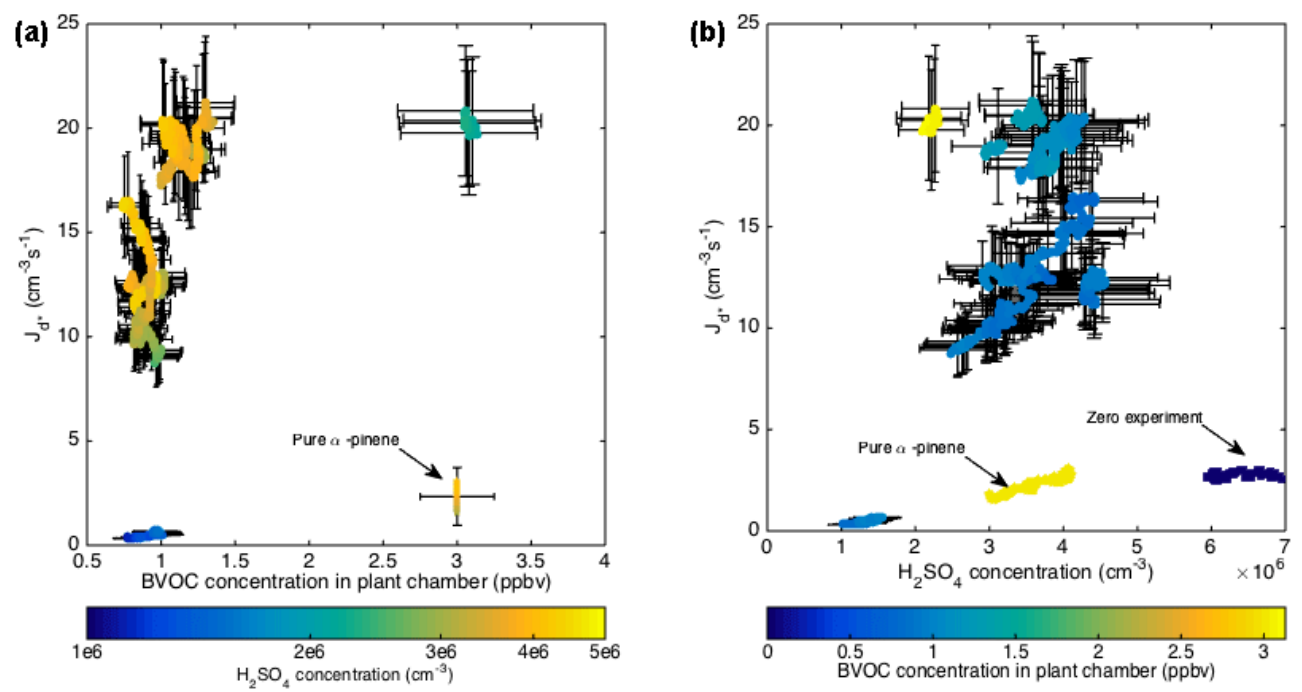

Figure 4. (a) Particle formation rates $(J)$ as function of BVOC concentration, and marker colours indicate the corresponding $\mathrm{H}_{2} \mathrm{SO}_{4}$ concentrations in log scales. (b) Particle formation rates $(J)$ as function of $\mathrm{H}_{2} \mathrm{SO}_{4}$ concentrations. Marker colours indicate the corresponding BVOC concentration from the inlet flow. Square markers show data from alpha-pinene experiments; star markers show a zero experiment with no BVOC added.

ing the following formulation for the formation rate $J$ :

$J=\frac{K \times[\mathrm{BVOC}]_{\mathrm{SS}} \times[\mathrm{Ox}]_{\mathrm{SS}} \times\left[\mathrm{H}_{2} \mathrm{SO}_{4}\right]}{\mathrm{CS}}$,

where the concentrations $[\mathrm{BVOC}]_{\mathrm{SS}}$ and $[\mathrm{Ox}]_{\mathrm{SS}}$ refer to steady-state concentrations of precursor BVOC and their oxidants, ozone and the hydroxyl radical. CS stands for the condensation sink. Despite findings reported in literature, little correlation could be found with this approach (see Table 2). However, when we used the VOC inflow rate $\left(Q_{\mathrm{BVOC}}, \mathrm{ob}-\right.$ tained from the flow rate from the plant chamber to the reaction chamber carrying the measured VOC concentration in the plant chamber, with dilution accounted for) multiplied with the sulfuric acid concentration, i.e. a parameterization of the form

$J=k \times Q_{[\mathrm{BVOC}]} \times\left[\mathrm{H}_{2} \mathrm{SO}_{4}\right]$,

we found very good correlation $\left(R^{2}=0.81\right)$ with the observed particle formation rate in the reaction chamber (as seen in Fig. 5). The coefficient $k$ in Eq. (7) can be derived from the least-square fit to our observation data, and in our experiments it was $1.1 \pm 0.1 \times 10^{-12} \mathrm{~cm}^{3}$, with $Q$ expressed as molecules $\left(\mathrm{cm}^{3} \mathrm{~s}\right)^{-1}$. Note that this formulation does not include a concentration of the organic compound, as commonly used, but rather a source rate of the precursor. However, it can be shown that Eq. (7) is a result of the same mechanism as Eq. (6), and the better correlation is due to better accuracy of the parameters in Eq. (7). This, and the rest of our findings in relation to different particle formation mechanisms in Sect. 3.3, and discuss the implications for atmospheric particle formation in Sect. 3.4.
Table 2. Coefficients of determination $\left(R^{2}\right)$ between the observed nanoCN formation rate $(J)$ and different parameterizations of nucleation mechanisms.

\begin{tabular}{lr}
\hline Parameterization & $R^{2}$ \\
\hline$\left[\mathrm{BVOC}_{\text {PlantChamber }}\right] \times\left[\mathrm{H}_{2} \mathrm{SO}_{4}\right]$ & 0.81 \\
{$\left[\mathrm{BVOC}_{\text {ReactionChamber }}\right] \times\left[\mathrm{H}_{2} \mathrm{SO}_{4}\right]$} & $0.111(-)$ \\
{$\left[\mathrm{BVOC}_{\text {ReactionChamber }}\right] \times\left[\mathrm{H}_{2} \mathrm{SO}_{4}\right] \times[\mathrm{OH}]$} & $0.031(-)$ \\
{$\left[\mathrm{BVOC}_{\text {ReactionChamber }}\right] \times\left[\mathrm{H}_{2} \mathrm{SO}_{4}\right] \times[\mathrm{O} 3]$} & $0.165(-)$ \\
{$\left[\mathrm{H}_{2} \mathrm{SO}_{4}\right]$} & 0.404 \\
{$\left[\mathrm{H}_{2} \mathrm{SO}_{4}\right]^{2}$} & 0.325 \\
\hline
\end{tabular}

(-) after the $R^{2}$ value means that the correlation was negative.

\subsection{Particle growth rates related to sulfuric acid and VOC concentrations}

To study the effect of sulfuric acid and plant-emitted BVOC on the early growth of particles, we obtained the growth rate of particles at the start of each particle formation burst from the time-difference analysis as described in Sect. 2.5. The results of the analysis are presented in Fig. 6 for two size ranges, $1.6-7 \mathrm{~nm}$ (the detection limits of the PSM and the CPC) and 7-15 nm (detection limits of the CPC and SMPS). Over the experiments performed during the campaign, the growth rate of fresh particles ranged from ca. 3 up to ca. $90 \mathrm{nmh}^{-1}$. During the no-ozone experiment on 23 September, particle growth rate could not be obtained due to the particles not reaching the CPC detection limit during the $3.5 \mathrm{~h}$ that ozone was off; therefore, we assume that the growth rate during this time was clearly below $2 \mathrm{nmh}^{-1}$. During the 


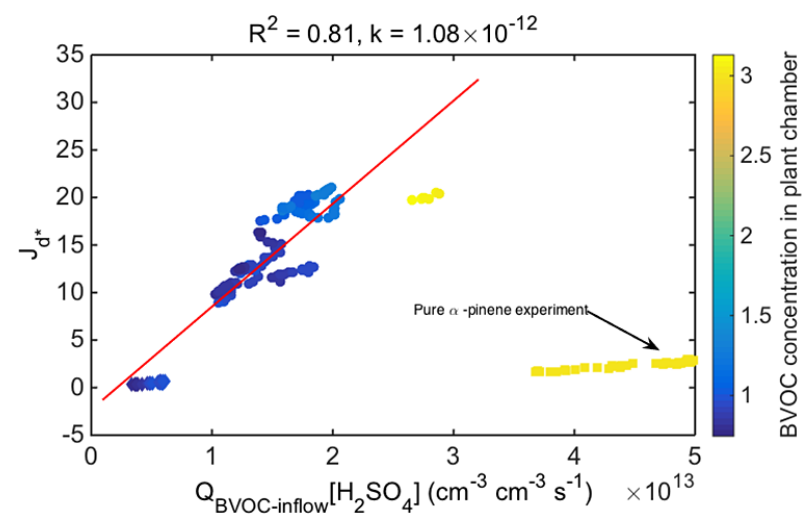

Figure 5. Particle formation rates $(J)$ as function of the product of BVOC inflow and sulfuric acid concentration. Marker colours indicate the corresponding monoterpene concentration from the inlet flow of JPAC reaction chamber. The pure $\alpha$-pinene experiments indicated in the figure were not included in the linear fit.

alpha-pinene experiment on 27 September, the growth rates differed from the general trend and they are therefore indicated in the result figures. We found that the growth rate of particles was well correlated with the BVOC concentration in the plant chamber at the start of the particle formation burst (Fig. 6a).

The growth rate of $1.6-7 \mathrm{~nm}$ particles was generally somewhat higher than for the larger particles; this is somewhat surprising, because recent literature (e.g. Kulmala et al., 2013) points towards slower growth at the early stages of particle formation. We suspect that the reason might be related to the temporal variation of the condensing species: quick oxidation of BVOC already in the chamber leads to higher low-volatility vapour concentrations at the start of the event. However, due to their short lifetime and the decline of precursor BVOC by oxidation, their concentration at the time particles have reached the size of $7 \mathrm{~nm}$ will have diminished, causing lower growth rates. The growth rate showed little correlation with the measured concentration of sulfuric acid (Fig. 6b). We interpret this as evidence of the growth of particles being dominated by the condensation of organic species resulting of the oxidation of plant-emitted BVOC, and this is also in line with literature reports that have estimated the contribution of sulfuric acid to particle growth to be 1 order of magnitude lower than the contribution of organics in boreal forest conditions (Boy et al., 2005; Iida et al., 2008; Paasonen et al., 2010). The same conclusion was reached in Roldin et al. (2015), where the gas phase was modelled nearexplicitly, and the growth of larger particles was analysed. Such a contribution would be lost in the growth signal of our experiments. It should also be noted that the maximum growth rate that sulfuric acid could theoretically contribute (following e.g. Nieminen et al., 2010) is of the order of 0.1$1 \mathrm{nmh}^{-1}$ with the observed $\mathrm{H}_{2} \mathrm{SO}_{4}$ concentrations.
As also found in the detailed modelling study by Roldin et al. (2015) (companion paper), particle growth occurs via condensation of low-volatility vapours to the surface of existing nanoparticles. These low-volatile vapours are considered to be the result of the oxidation of BVOCs, and therefore, their concentration should be proportional to the product of the BVOC concentration and the concentration of the oxidant. As the growth rate is theoretically proportional to the condensing vapour concentration, we compared the observed growth rates to the product of BVOC (we chose monoterpene as the dominant BVOC) and the measured ozone and the observed $\mathrm{OH}$ concentrations (Fig. 6c and d, respectively). We observed that the growth rate correlated very well with the product of ozone and monoterpenes, but did not correlate with the product of $\mathrm{OH}$ and monoterpenes. This suggests that oxidation by ozone is the limiting factor in the production of condensable vapours from monoterpene precursors; this supports the findings of Hao et al. (2011), who came to similar conclusions using a modelling approach. We also want to point out that we found clear low outliers in the growth rate data when we performed an experiment where we only used $\alpha$-pinene as a BVOC precursor instead of real plant emissions. This suggests that the dominant BVOC acting as a precursor for the condensing extremely low volatility VOC (EVOC) is not $\alpha$-pinene, but some other emitted BVOC.

\subsection{Discussion of the nanoCN formation mechanism}

Recent studies in the particle formation mechanism and the participating species have shown that organic compounds are likely to participate in the nucleation mechanism together with sulfuric acid, and some stabilizing bases, such as amines are also considered (see e.g. Riccobono et al., 2014; Zhang et al., 2004; Almeida et al., 2013; Schobesberger et al., 2013). In this study we did not have the capability to observe the full chemical composition of all possible species; the aim was to perform experiments as close to realistic boreal conditions as possible, and relate our findings to real-world conditions. Therefore, we will explain our findings in the light of observable parameters, and discuss the implications of our results. As shown in Sect. 3.1, the best correlation of the observed particle formation rate was found using the BVOC influx and sulfuric acid concentration as the measurable independent parameters (see Eq. 6). The approach taken in earlier studies, of assuming that the concentration of the organic compound participating in particle formation can be estimated from the product of the concentrations of the BVOC precursor and the oxidant, as in Eq. (6) did not show agreement with our data. The reason for this is likely due to the low concentrations used, which led to almost all BVOC precursors being consumed during UV-on periods, and thus the measurement noise for reaction chamber measurements makes predictions using Eq. (6) inconclusive. However, as we found that the BVOC influx into the reaction chamber clearly influenced nanoCN formation, and the expression in Eq. (7) resulted 

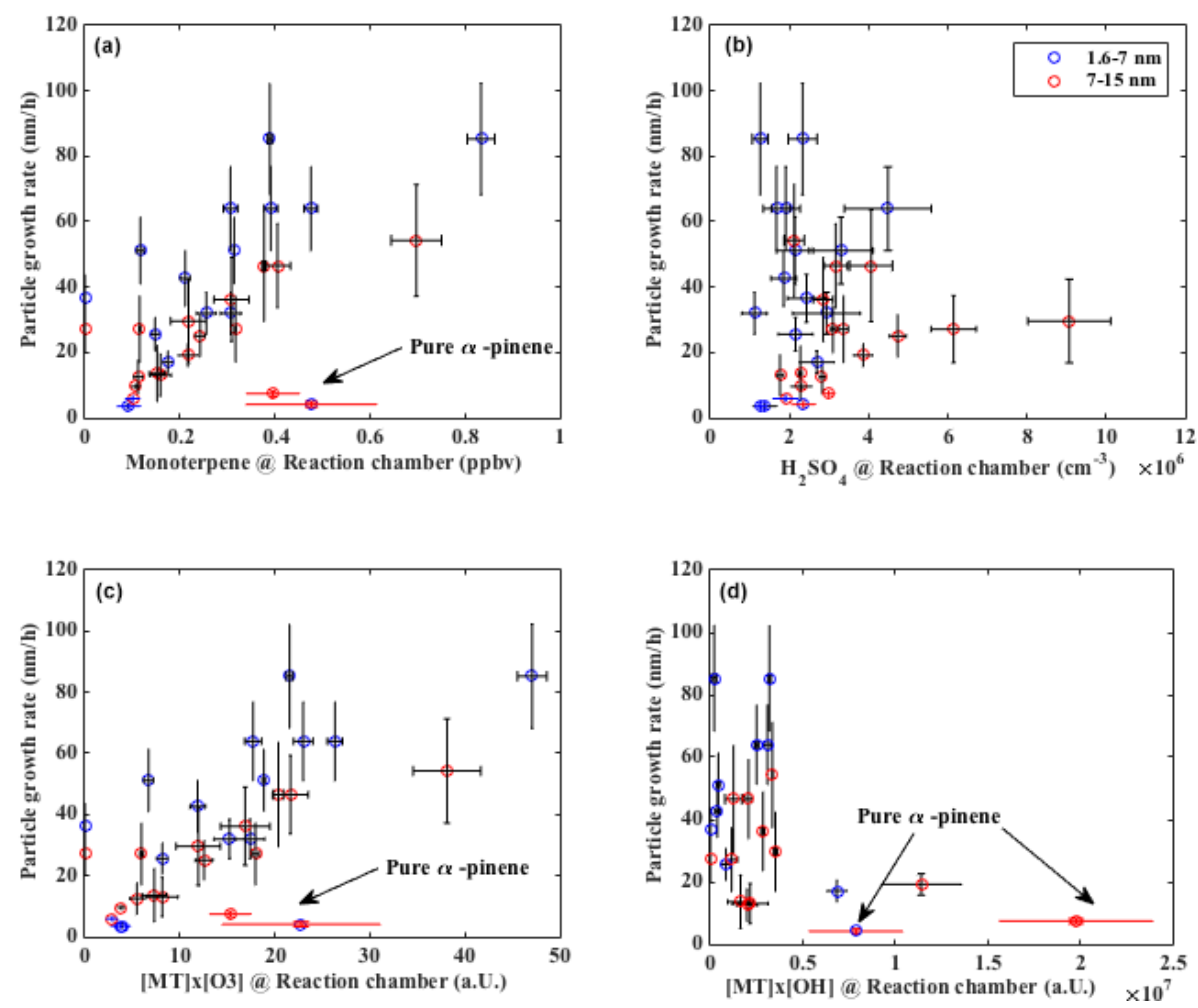

Figure 6. Particle growth rates (GR) at the beginning of the particle formation burst as function of (a) monoterpene concentrations in the JPAC reaction chamber and (b) $\mathrm{H}_{2} \mathrm{SO}_{4}$ concentrations in the JPAC reaction chamber. (c) Proxy concentrations of oxidation products of monoterpenes by $\mathrm{O}_{3}$ in the JPAC reaction chamber; (d) proxy concentrations of oxidation products of monoterpenes by OH in the JPAC reaction chamber. Red squares are growth rates of particles ranging from 1.6 to $7 \mathrm{~nm}$, and blues markers indicates growth rates of particles with a diameter of $7-15 \mathrm{~nm}$.

in good correlation, we consider it likely that BVOC were involved in the formation process. To explain the findings, we show using a conceptual mechanism involving a reaction system with $\mathrm{BVOC}$ and $\mathrm{H}_{2} \mathrm{SO}_{4}$, and leading to nanoCN formation, that our findings are in line with the proposed mechanism. The reaction system is based on the principle of maximum simplicity, which makes it useful also in the field, where the degree of gas phase and particle characterization may often be lower than in laboratory conditions.

In the conceptual system, the source strength of the precursor of BVOC is determined by the concentration of BVOC in the plant chamber and the flow rate between the chambers. The resulting source rate is denoted by $q$. The total BVOC react with oxidants with a lumped reaction rate constant $k_{\mathrm{ox}}$, producing oxidized compounds; a small fraction (denoted by $n$ ) of the BVOC is oxidized to produce a product that is able to form clusters with sulfuric acid (NucOx). This compound, in turn, forms nanoCN with sulfuric acid with a reaction rate $k_{J}$. In addition, the major fraction (denoted by $i=(1-n)$ ) of BVOC may react to form compounds that do not participate in nanoCN formation $(\mathrm{OxVOC}$, inert in terms of nanoCN formation), as well as be lost to dilution and to the wall. The same applies to the nanoCN-forming compounds: they may react further or be lost to the walls and by dilution. The simplified mechanism is described by the following set of reactions, and a schematic illustration is given in Fig. 7.

$$
\begin{aligned}
& Q_{\text {inflow }} \stackrel{q}{\rightarrow} \text { BVOC } \\
& \cdot \mathrm{BVOC}+\mathrm{OX} \stackrel{k_{\mathrm{OX}}}{\longrightarrow} i \cdot \mathrm{OxVOC}+n \cdot \mathrm{NucOX} \\
& \mathrm{BVOC}+(\mathrm{X}) \stackrel{\gamma_{\mathrm{BVOC}}}{\longrightarrow} \text { dilution }+ \text { losses } \\
& \mathrm{NucOX}+\mathrm{H}_{2} \mathrm{SO}_{4} \stackrel{k_{J}}{\longrightarrow} \text { nanoCN } \\
& \text { NucOx }+(\mathrm{X}) \stackrel{\gamma_{\mathrm{NucOX}}}{\longrightarrow} \text { dilution + losses }
\end{aligned}
$$

$\gamma_{\mathrm{BVOC}}$ and $\gamma_{\mathrm{NuCOX}}$ stand for the total loss rate of BVOC and NucOx, respectively, and by loss we mean either losses to walls or dilution, or to chemical pathways that do no lead to particle formation. From our measurements, we know that the BVOC is in steady state during the analysis period, and we can assume that $\mathrm{NucOx}$ is also in steady state. Now we can solve for the concentrations of BVOC and NucOx using the steady-state approximation, setting the time change of these concentrations to zero. The BVOC concentration now is

$[\mathrm{BVOC}]=\frac{q}{n \cdot k_{\mathrm{ox}}[\mathrm{OX}]+i \cdot k_{\mathrm{ox}}[\mathrm{OX}]+\gamma_{\mathrm{BVOC}}}$, 


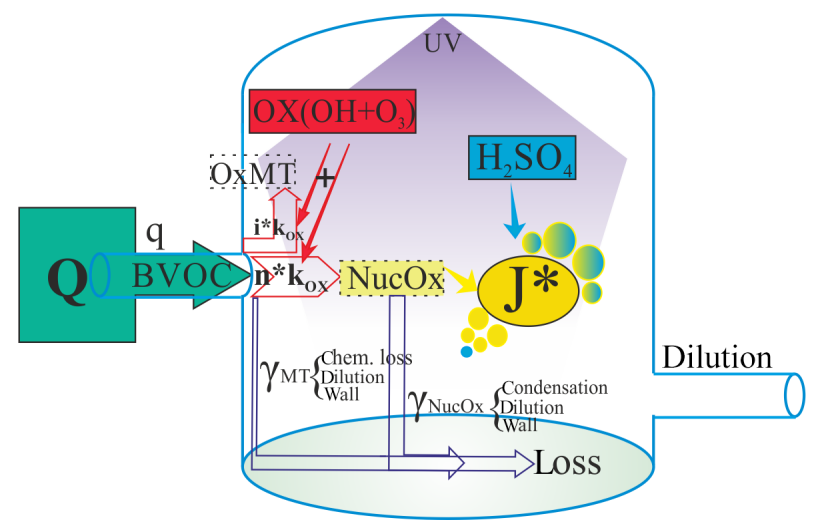

Figure 7. A conceptual figure of the gas-phase reaction system leading to the formation of nanoCN in the JPAC chamber. BVOC are emitted in the plant chamber $(Q)$ and then transported to the reaction chamber in the connecting flow, leading to a source rate $q$ in the reaction volume. BVOC then reacts, producing oxidized products that are either able to participate in nanoCN formation ( $\mathrm{NucOx}$ ) or inert products (OxVOC), with fractional yields $n$ and $i$, respectively. BVOC can also be lost by other pathways. NucOx has two fates: react with $\mathrm{H}_{2} \mathrm{SO}_{4}$ or be lost by condensation (to particles or the wall) or dilution. The loss process is dominant. The reaction with $\mathrm{H}_{2} \mathrm{SO}_{4}$ produces nanoCN.

and the NucOX concentration is

$[\mathrm{NucOX}]=\frac{n \cdot k_{\mathrm{ox}}[\mathrm{BVOC}][\mathrm{OX}]}{k_{J}\left[\mathrm{H}_{2} \mathrm{SO}_{4}\right]+\gamma_{\mathrm{NucOX}}}$.

Solving for the nanoCN formation rate $J$, which we get from reaction (R4) as $J=k_{J}\left[\mathrm{H}_{2} \mathrm{SO}_{4}\right][\mathrm{NucOx}]$, we will arrive at

$J=\frac{q}{\left(1+\frac{i \cdot k_{\mathrm{OX}}[\mathrm{OX}]+\gamma_{\mathrm{BVOC}}}{n \cdot k_{\mathrm{OX}}[\mathrm{OX}]}\right)\left(1+\frac{\gamma_{\mathrm{NucOX}}}{k_{J}\left[\mathrm{H}_{2} \mathrm{SO}_{4}\right]}\right)}$.

In our system, the oxidizing reactions are dominating loss reactions for BVOC during UV-on periods (see e.g. Mentel et al., 2009), and therefore $i \cdot k_{\mathrm{OX}}[\mathrm{OX}]+\gamma_{\mathrm{BVOC}} \approx i \cdot k_{\mathrm{OX}}[\mathrm{OX}]$; it should be noted that this assumption does not necessarily hold in the atmosphere. For the nucleation reaction, $\gamma \gamma_{\mathrm{NucO}}$ is likely to be significantly greater than the nucleation channel rate (this can be assumed from estimating the amount of molecules that form a new particle) and the second term in the denominator reduces to $\gamma_{\mathrm{NucOx}} / k_{J}\left[\mathrm{H}_{2} \mathrm{SO}_{4}\right]$. If we now also assume that only a small fraction of BVOC is converted into NucOx $(i \gg n$, leading to $(1+i / n) \approx i / n)$, then the previous equation reduces to

$J=q \frac{n}{i} \frac{k_{J}\left[\mathrm{H}_{2} \mathrm{SO}_{4}\right]}{\gamma_{\mathrm{NucOX}}}=K \times q \times\left[\mathrm{H}_{2} \mathrm{SO}_{4}\right]$,

where the parameter is defined as $K=\frac{n}{i} \frac{k_{J}}{\gamma_{\text {NucOX }}}$. Now, the nucleation rate is expressed only as a function of measured quantities, namely the BVOC source rate $q$ and the measured sulfuric acid concentration, multiplied by the constant $K$ that depends on the relative molecular yield of nucleating oxidation products, the rate coefficient $k_{J}$, and the loss rate of $\mathrm{Nu}$ cOX. The dependence on the sulfuric acid causes an implicit dependence on the photochemical oxidation rate; an $\mathrm{OH}$ dependence found by Kiendler-Scharr et al. (2009) is thus still observable in our experiments. As the isoprene levels were very low in our experiments, the isoprene inhibition effect could not be observed.

The reaction system presented above postulates that $\mathrm{Nu}-$ $\mathrm{cOx}$ are rapidly formed from oxidation of plant BVOC with a yield that is comparatively small compared to the yield of the total oxidized BVOC. In addition, it states that the rate of formation of nanoCN depends on the concentrations of both $\mathrm{NucOx}$ and $\mathrm{H}_{2} \mathrm{SO}_{4}$, both of which are regulated by their respective sources and losses. For $\mathrm{H}_{2} \mathrm{SO}_{4}$, we have experimental knowledge of the concentration, which accounts for its inclusion in the expression for nanoCN formation rate. As NucOx remains experimentally unquantified, its concentration is not included directly, but its contribution can be estimated from the measured source rate. It should be noted that the formulation given in Eq. (11) is equivalent to Eq. (6) in a situation where $\mathrm{BVOC}$ are quickly oxidized by $\mathrm{OH}$ to form NucOx. In principle, the steady-state concentration of NucOx could be estimated also from the product of BVOC in the plant chamber and the oxidant concentration, assuming known loss rates. However, as in our experiments almost all of the BVOC is oxidised, and the concentration levels in the reaction chamber are close to the detection limit of our instrumentation. Thus, the measurements of BVOC concentration during light-on period is dominated by random error, which yields bad results for correlation analysis (Table 2; see also Supplement). Substituting the source rate and applying the assumptions leading to Eq. (11), we managed to describe the mechanism using observations with lower relative uncertainties, which enables us to state that our observed data for $J$ indeed shows the correlation that is expected from the postulated reactions. This information was also used to perform detailed modelling of the gas phase chemistry and particle formation and growth in the plant chamber system; this is presented in a companion paper (Roldin et al., 2015), which describes in detail the simulations and also focuses on particle growth.

The factor $n / i=n /(1-n) \approx n$ (for $n \ll 1)$ conceptually represents the stoichiometric fractional yield of oxidized BVOC capable of participating in the particle formation process. Based on the recent results by Ehn et al. (2014), it is possible that these compounds are similar to the ELVOC identified in their experiment. Ehn and co-authors found a stoichiometric yield of a few percent in their experiment with alpha-pinene; similar yields could be expected in our experiments. In this study, the chemistry was fairly constant, with low $\mathrm{NO}_{\mathrm{x}}$ values in the chamber. Wildt et al. (2014) performed experiments in JPAC where they varied the amount of $\mathrm{NO}_{\mathrm{x}}$, and found that high $\mathrm{NO}_{\mathrm{x}}$ inhibits particle formation; this was attributed to higher formation rate of $\mathrm{RO}_{2}$ per- 
mutation reaction products (PRPs) at low- $\mathrm{NO}_{\mathrm{x}}$ conditions, whereas at high- $\mathrm{NO}_{\mathrm{x}}$ conditions $\mathrm{RO}_{2}$ reacts predominantly with NO (see Wildt et al., 2014 for details). For our case, this would mean that the ratio $n / i$ gets smaller, and less NucOX gets produced.

The factor $\left[\mathrm{H}_{2} \mathrm{SO}_{4}\right] \cdot k_{J} / \gamma_{\mathrm{NucO}}$ describes the ratio between the amount of $\mathrm{NucOx}$ lost by the nucleation process and the loss by other processes. We can estimate this ratio qualitatively: the maximum value for $k_{J}$ can be estimated from kinetic gas theory, and is at maximum of the order of $10^{-10} \mathrm{~cm}^{3} \mathrm{~s}^{-1}$ (Weber et al., 1996). Thus the numerator is necessarily less than $10^{-3} \mathrm{~s}^{-1}$ in our experiments. Comparing this to the condensation sink, which was of the order of $5 \times 10^{-3} \mathrm{~s}^{-1}$, and the wall losses for NucOx of the order of $10^{-2} \mathrm{~s}^{-1}$ (assuming similar wall losses as in Ehn et al., 2014), we can see that the nucleation process itself has little influence on the concentration of NucOx. In our experiments, it is likely that the wall losses dominated the loss of NucOx, leading to a minor influence of the condensation sink on the formation rate; however, in field conditions it is likely that the condensation sink dominates and $J$ is partly regulated by CS. This has been shown for several field studies previously (e.g. Dal Maso et al., 2007). In their study, Metzger et al. (2010) estimated the concentration of NucOx from the particle growth rate; based on their approach, the yield of NucOx was $0.025 \%$ of the VOC concentration. In their study, the growth rate was used also for the determination of the formation rate of nanoCN, which in our study was not required. Therefore, we present an independent confirmation of the results of Metzger et al. (2010) using different methodology. As shown in studies by Mentel et al. (2009, 2013) and Kiendler-Scharr et al. (2009), the mixture of BVOC has a profound effect on the particle formation, with pure alpha-pinene producing markedly less aerosol than real plant BVOC mixtures. This is again confirmed by our experiments. For similar total BVOC source rate, pure alpha-pinene produced ca. 1 order of magnitude lower particle formation rates at equivalent $\mathrm{H}_{2} \mathrm{SO}_{4}$ concentrations. We interpret this as a sign that the yield of NucOx from alphapinene is much lower than for real plant emissions. In their experiment in the CLOUD chamber, Riccobono et al. (2014) used pinanediol to induce particle formation with sulfuric acid, and arrived at a parameterization for the formation of the form $J=k^{\prime}\left[\mathrm{H}_{2} \mathrm{SO}_{4}\right]^{2}[\mathrm{BioOxOrg}]^{1}$. Pinanediol is an oxidation product of alpha-pinene, and we speculate that the differences between the results of Riccobono et al. (2014) could be caused by a different oxidation path. It should be noted, that the emission matrix effect of realistic tree emissions seems to mostly affect nucleation and early growth of particles, and not so much particle growth (Mentel et al., 2009; Kiendler-Scharr et al., 2009); this would indicate that realistic trees produce precursors that effectively nucleate, but at low concentrations, while low-volatility compounds that mostly condense on the particles are also formed by pure compounds. However, one should note that the appar- ent weakness of alpha-pinene relative to real emission mixtures holds only for nucleation and early growth; growth of larger particles is not affected (Mentel et al., 2009). In the Ehn et al. (2014) study, SOA formation was studied by the growth of existing seed particles, and no direct nucleation studies were performed; our results, on the contrary, are relevant for the nanoCN formation and very early growth. Additionally, ELVOC can be formed also from other sources than alpha-pinene; some ELVOC may participate in nanoCN formation while others only participate in growth. Above, we have shown that our findings support the hypothesis that oxidized products of plant BVOC emissions enhance nanoCN formation. Our results for the growth rates of particles show that in contrast to particle formation, sulfuric acid played little role in nanoCN growth to larger sizes. However, the concentration of monoterpene (or BVOC in general, as total BVOC and monoterpene were strongly correlated) correlated very well with the growth rate of small particles, the only exception being pure alpha-pinene. Correlations corresponding to growth occurring by $\mathrm{OH}$-induced oxidation reaction products could not be observed in our experiments, while the correlations with estimations of BVOC ozonolysis products were found. As the growth rates of particles were obtained at the very start of particle formation when concentrations both in the gas and particle phase were in strong transition, we cannot reliably estimate the concentrations and yields of the condensing vapours. To do this, detailed modelling of the gas and particle dynamics is required; this work has been performed in the MALTE modelling study of Roldin et al. (2015). While the correlations are not conclusive evidence of the ozonolysis products governing nanoparticle growth, the data seems to suggest that this is likely, at least for boreal forests. One should also note that our results do not exclude the possibility that some other compound than the BVOC (candidates include for example amines), co-emitted by the plants, is the critical compound for particle formation. However, in our case the data suggest that it is emitted proportionally to the other BVOC. From existing literature, we could not find a description of a mechanism that would lead to the emission of amines in the same manner and proportionally to BVOC, and therefore this remains an open question. The key aim of our study was to quantify the effect of boreal BVOC on the particle formation rates at realistic concentration levels; therefore, we also compared the rates with which the BVOC were introduced to the reaction chamber to ambient rates reported in literature. In boreal forests, average monoterpene emission rates to the atmosphere vary between 20 and $100 \mathrm{ng} \mathrm{s}^{-1} \mathrm{~m}^{-2}$ depending on the season and type of vegetation (Spanke et al., 2001). For our experiment, the ambient emission rate needs to be compared to the rate at which BVOC were introduced to the reaction chamber, i.e. the source rate $q$ in our simplified reaction system (Reaction R2). We measured the source rate into the reaction chamber by measuring the concentration in the plant chamber outlet. Taking dilution into ac- 
count, a measurement of a $1 \mathrm{ppb}$ concentration at the outlet of the plant chamber corresponds to a BVOC source rate of $1.35 \times 10^{13}$ molecules $\mathrm{s}^{-1}$ into the $1.45 \mathrm{~m}^{3}$ chamber, corresponding to $2.08 \mathrm{ng} \mathrm{s}^{-1} \mathrm{~m}^{-3}$ (assuming monoterpene, $M=$ $136 \mathrm{~g} \mathrm{~mol}^{-1}=2.26 \times 10^{-22} \mathrm{~g} \mathrm{molecule}^{-1}$ ). Thus, the source rate in our chamber can be estimated as $1.5-8 \mathrm{ng} \mathrm{s}^{-1} \mathrm{~m}^{-3}$. To compare this to ambient conditions, we need to estimate the "reaction volume" in the atmosphere. Spanke et al. (2001) observed that the area of the strongest chemical degradation of monoterpenes in the boreal forest occurs near the top of the forest canopy. We can therefore assume that the reaction volume extends some tens of metres above the forest. Also, as discussed before, we assume that the oxidation of emitted BVOC occurs quickly after it is exposed to an oxidizing atmosphere. Thus we can estimate the "reaction volume" to be a layer of roughly $10-50 \mathrm{~m}$ thickness, centred at the VOC-emitting vegetation, giving a maximum source rate into the ambient reaction volume of $20-100 \mathrm{ng} \mathrm{s}^{-1} \mathrm{~m}^{-2} \mathrm{di}-$ vided by $10-50 \mathrm{~m}$, resulting in $0.04-10 \mathrm{ng} \mathrm{s}^{-1} \mathrm{~m}^{-3}$, which is directly comparable to our chamber. The oxidation speed in our experiments was higher than is likely for most cases in the atmosphere, but the concentrations of BVOC were comparable. High oxidant concentrations often remain a necessity in experiments simulating secondary aerosol number and mass formation, due to short lifetimes of particles in chamber settings. Our analysis expressing formation rates as a function of precursor source rates might be useful for currently used secondary aerosol experiments in which very high oxidant concentrations are used (Kang et al., 2007); in these cases, oxidant concentrations can exceed our concentrations by orders of magnitude, and thus nearly all in-chamber VOC would be exhausted, leading to similar problems with correlation analysis. Replacing the BVOC concentration in the chamber with the source rate provides a more stable measurable quantity for formation rate analysis.

\section{Conclusions}

We performed controlled nanoCN formation experiments in the Jülich Plant Atmosphere Chamber set-up using boreal forest BVOC emitters and simultaneously monitoring BVOC levels, $\mathrm{H}_{2} \mathrm{SO}_{4}$ concentration and nanoCN concentration. The experiments allowed us to observe the formation rate of nanoCN $(J)$ as a function of $\mathrm{H}_{2} \mathrm{SO}_{4}$ concentration without need for the determination of the particle growth rate, which has been reported to cause the largest uncertainties in the nanoCN formation rate determination. To our knowledge, this is the first time that nanoCN, $\mathrm{H}_{2} \mathrm{SO}_{4}$, and realistic levels and mixtures of BVOC have been observed in controlled laboratory conditions.

In agreement with many other studies, (Kulmala et al., 2013; Almeida et al., 2013; Schobesberger et al., 2013; Wildt et al., 2014; Riccobono et al., 2014), we found conclusive evidence that realistic boreal forest BVOC directly in- fluence nanoparticle formation rates at levels that are similar to atmospheric levels, while sulfuric acid is also required for the process. In addition we found that realistic BVOC mixtures produce higher particle formation rates than pure $\alpha$-pinene, again in agreement with previous studies (Mentel et al., 2009). We found no correlation for the formation rate with steady-state observations of BVOC concentrations in the reaction volume; however, we found high correlation when using BVOC source rate as the independent variable. We found that such a correlation is consistent with a gas-phase mechanism in which BVOC is quickly oxidized to form a compound that is able to stabilise $\mathrm{H}_{2} \mathrm{SO}_{4}$, but also rapidly condenses on existing particulate matter and available wall surfaces. Possible candidates for such compounds are the recently observed ELVOC (Ehn et al., 2014), which are formed at least by ozonolysis. Our observations are not conclusive in determining the oxidation pathway for the formation of the nucleating compounds. We could parameterise the formation rate in our chamber as a function of the BVOC source rate and the sulfuric acid concentration, yielding $J=1.1 \times 10^{-12} \mathrm{~cm}^{3} \times Q_{\mathrm{BVOC}} \times\left[\mathrm{H}_{2} \mathrm{SO}_{4}\right]$, with $Q$ given in units of molecules $\mathrm{cm}^{-3}$ per second, and $\left[\mathrm{H}_{2} \mathrm{SO}_{4}\right]$ in molecules $\mathrm{cm}^{-3}$. To translate this for application with atmospheric observations, we obtained $J=4.5 \times$ $10^{-6} \mathrm{~m}^{3} \mathrm{ng}^{-1} \times E_{\mathrm{BVOC}} \mathrm{h}^{-1} \times\left[\mathrm{H}_{2} \mathrm{SO}_{4}\right]$, in which $E_{\mathrm{BVOC}}$ is the emission rate of BVOC per unit area of boreal forest, and $h$ is the height of the layer in which particle formation occurs. The prefactor for $J$ is expected to be dependent on the BVOC mixture, in line with observations of e.g. Mentel et al. (2009, 2013), on $\mathrm{NO}_{\mathrm{x}}$ concentrations (Wildt et al., 2014), and possibly also the $\mathrm{OH}$ concentration (e.g. Kiendler-Scharr et al., 2009, 2012), and it should be scaled by the difference of the NucOx loss rates between the atmosphere and chamber.

After formation of the initial nuclei, oxidized plant emissions are responsible for the main part of the aerosol growth to larger sizes. Thus, plant derived organic compounds enhance aerosol formation in both the formation and the growth phase. In the atmosphere, with enough oxidants present, the strength of the nucleation source is determined by the availability of precursor BVOC, and by sulfuric acid concentrations. For growth, a larger fraction of the BVOC oxidation products are condensing and the slower oxidation by ozonolysis steers the pace of the growth.

Our findings are a step towards more exact predictions of the response of atmospheric aerosol formation to future changes in trace gas emissions and land use changes. The nucleation process presents an upper limit for the cloud condensation nuclei $(\mathrm{CCN})$ production; loss processes such as deposition and coagulation result in only a fraction of formed particles reaching $\mathrm{CCN}$ size. The faster the nanoparticles grow, the higher this fraction is. As plant-emitted organics enhance both the maximum number and the survival probability of potential CCN, biogenic activity and stress impacts on plants may play a significant role in negative climatic feedbacks via aerosol effects (Kulmala et al., 2004, 2014). Also, the impact 
of organic emissions on particle concentrations is enhanced compared to a situation where only sulfuric acid determines the initial nuclei formation rate.

More generally, the magnitude of the BVOC effect depends on the $\mathrm{SO}_{2}$ concentration. In $\mathrm{SO}_{2}$-polluted environments, the effect of variation in BVOC will diminish and particle formation is mainly determined by the $\mathrm{H}_{2} \mathrm{SO}_{4}$ concentration. At low $\mathrm{SO}_{2}$ concentrations, the BVOC effect becomes more dominant. Therefore, the effect of BVOC cannot be ignored when modelling tropospheric aerosol formation in clean conditions, such as the pre-industrial period (Merikanto et al., 2010) or rural areas, or when making projections for future aerosol loadings (e.g. Arneth et al., 2010). In these cases $\mathrm{SO}_{2}$ levels are likely to be low, and the BVOC effect on nucleation has potentially a major impact on particle and $\mathrm{CCN}$ formation.

\section{The Supplement related to this article is available online at doi:10.5194/acp-16-1955-2016-supplement.}

Acknowledgements. This work was funded by the Finnish Academy, project no. 128731, the Maj and Tor Nessling foundation (project 2009362), the FCoE (The Centre of Excellence in Atmospheric Science - From Molecular and Biological processes to the Global Climate (ATM)), and the PEGASOS (Pan-European Gas-Aerosols-climate interaction Study, project No. FP7- ENV2010-265148).

Edited by: N. Mihalopoulos

\section{References}

Almeida, J., Schobesberger, S., Kurten, A., Ortega, I. K., Kupiainen-Maatta, O., Praplan, A. P., Adamov, A., Amorim, A., Bianchi, F., Breitenlechner, M., David, A., Dommen, J., Donahue, N. M., Downard, A., Dunne, E., Duplissy, J., Ehrhart, S., Flagan, R. C., Franchin, A., Guida, R., Hakala, J., Hansel, A., Heinritzi, M., Henschel, H., Jokinen, T., Junninen, H., Kajos, M., Kangasluoma, J., Keskinen, H., Kupc, A., Kurten, T., Kvashin, A. N., Laaksonen, A., Lehtipalo, K., Leiminger, M., Leppa, J., Loukonen, V., Makhmutov, V., Mathot, S., McGrath, M. J., Nieminen, T., Olenius, T., Onnela, A., Petaja, T., Riccobono, F., Riipinen, I., Rissanen, M., Rondo, L., Ruuskanen, T., Santos, F. D., Sarnela, N., Schallhart, S., Schnitzhofer, R., Seinfeld, J. H., Simon, M., Sipila, M., Stozhkov, Y., Stratmann, F., Tome, A., Trostl, J., Tsagkogeorgas, G., Vaattovaara, P., Viisanen, Y., Virtanen, A., Vrtala, A., Wagner, P. E., Weingartner, E., Wex, H., Williamson, C., Wimmer, D., Ye, P., Yli-Juuti, T., Carslaw, K. S., Kulmala, M., Curtius, J., Baltensperger, U., Worsnop, D. R., Vehkamaki, H., and Kirkby, J.: Molecular understanding of sulphuric acid-amine particle nucleation in the atmosphere, Nature, 502, 359-363, doi:10.1038/nature12663, 2013.
Arneth, A., Unger, N., Kulmala, M., and Andreae, M.: Clean the Air, Heat the Planet?, Science, 326, 672-673, doi:10.1126/science.1181568, 2010.

Ball, S., Hanson, D., Eisele, F., and McMurry, P.: Laboratory studies of particle nucleation: Initial results for $\mathrm{H}_{2} \mathrm{SO}_{4}, \mathrm{H}_{2} \mathrm{O}$, and $\mathrm{NH}_{3}$ vapors, J. Geophys. Res.-Atmos., 104, 23709-23718, 1999.

Berndt, T., Stratmann, F., Sipilä, M., Vanhanen, J., Petäjä, T., Mikkilä, J., Grüner, A., Spindler, G., Lee Mauldin III, R., Curtius, J., Kulmala, M., and Heintzenberg, J.: Laboratory study on new particle formation from the reaction $\mathrm{OH}+\mathrm{SO}_{2}$ : influence of experimental conditions, $\mathrm{H}_{2} \mathrm{O}$ vapour, $\mathrm{NH}_{3}$ and the amine tert-butylamine on the overall process, Atmos. Chem. Phys., 10, 7101-7116, doi:10.5194/acp-10-7101-2010, 2010.

Boy, M., Kulmala, M., Ruuskanen, T. M., Pihlatie, M., Reissell, A., Aalto, P. P., Keronen, P., Dal Maso, M., Hellen, H., Hakola, H., Jansson, R., Hanke, M., and Arnold, F.: Sulphuric acid closure and contribution to nucleation mode particle growth, Atmos. Chem. Phys., 5, 863-878, doi:10.5194/acp-5-863-2005, 2005.

Boy, M., Hellmuth, O., Korhonen, H., Nilsson, E. D., ReVelle, D., Turnipseed, A., Arnold, F., and Kulmala, M.: MALTE - model to predict new aerosol formation in the lower troposphere, Atmos. Chem. Phys., 6, 4499-4517, doi:10.5194/acp-6-4499-2006, 2006.

Dal Maso, M., Kulmala, M., Lehtinen, K. E. J., Mäkelä, J. M., Aalto, P. P., and ODowd, C.: Condensation and coagulation sinks and formation of nucleation mode particles in coastal and boreal forest boundary layers, J. Geophys. Res. Atmos., 107, 8097, doi:10.1029/2001JD001053, 2002.

Dal Maso, M., Sogacheva, L., Aalto, P., Riipinen, I., Komppula, M., Tunved, P., Korhonen, L., Suur-Uski, V., Hirsikko, A., Kurten, T., Kerminen, V., Lihavainen, H., Viisanen, Y., Hansson, H., and Kulmala, M.: Aerosol size distribution measurements at four Nordic field stations: identification, analysis and trajectory analysis of new particle formation bursts, Tellus B, 59, 350-361, doi:10.1111/j.1600-0889.2007.00267.x, 2007.

Ehn, M., Thornton, J. A., Kleist, E., Sipila, M., Junninen, H., Pullinen, I., Springer, M., Rubach, F., Tillmann, R., Lee, B., LopezHilfiker, F., Andres, S., Acir, I.-H., Rissanen, M., Jokinen, T., Schobesberger, S., Kangasluoma, J., Kontkanen, J., Nieminen, T., Kurten, T., Nielsen, L. B., Jorgensen, S., Kjaergaard, H. G., Canagaratna, M., Maso, M. D., Berndt, T., Petaja, T., Wahner, A., Kerminen, V.-M., Kulmala, M., Worsnop, D. R., Wildt, J., and Mentel, T. F.: A large source of low-volatility secondary organic aerosol, Nature, 506, 476-479, doi:10.1038/nature13032, 2014.

Hamed, A., Joutsensaari, J., Mikkonen, S., Sogacheva, L., Dal Maso, M., Kulmala, M., Cavalli, F., Fuzzi, S., Facchini, M. C., Decesari, S., Mircea, M., Lehtinen, K. E. J., and Laaksonen, A.: Nucleation and growth of new particles in Po Valley, Italy, Atmos. Chem. Phys., 7, 355-376, doi:10.5194/acp-7-355-2007, 2007.

Hamed, A., Birmili, W., Joutsensaari, J., Mikkonen, S., Asmi, A., Wehner, B., Spindler, G., Jaatinen, A., Wiedensohler, A., Korhonen, H., Lehtinen, K. E. J., and Laaksonen, A.: Changes in the production rate of secondary aerosol particles in Central Europe in view of decreasing SO2 emissions between 1996 and 2006, Atmos. Chem. Phys., 10, 1071-1091, doi:10.5194/acp-10-10712010, 2010. 
Hao, L. Q., Yli-Pirilä, P., Tiitta, P., Romakkaniemi, S., Vaattovaara, P., Kajos, M. K., Rinne, J., Heijari, J., Kortelainen, A., Miettinen, P., Kroll, J. H., Holopainen, J. K., Smith, J. N., Joutsensaari, J., Kulmala, M., Worsnop, D. R., and Laaksonen, A.: New particle formation from the oxidation of direct emissions of pine seedlings, Atmos. Chem. Phys., 9, 8121-8137, doi:10.5194/acp9-8121-2009, 2009.

Hao, L. Q., Romakkaniemi, S., Yli-Pirilä, P., Joutsensaari, J., Kortelainen, A., Kroll, J. H., Miettinen, P., Vaattovaara, P., Tiitta, P., Jaatinen, A., Kajos, M. K., Holopainen, J. K., Heijari, J., Rinne, J., Kulmala, M., Worsnop, D. R., Smith, J. N., and Laaksonen, A.: Mass yields of secondary organic aerosols from the oxidation of a-pinene and real plant emissions, Atmos. Chem. Phys., 11, 1367-1378, doi:10.5194/acp-11-1367-2011, 2011.

Heiden, A. C., Kobel, K., Langebartels, C., Schuh-Thomas, G., and Wildt, J.: Emissions of oxygenated volatile organic compounds from plants - part I: Emissions from lipoxygenase activity, J. Atmos. Chem., 45, 143-172, 2003.

Iida, K., Stolzenburg, M. R., McMurry, P. H., and Smith, J. N.: Estimating nanoparticle growth rates from size- dependent charged fractions, J. Geophys. Res., 113, D05207, doi:10.1029/2007JD009260, 2008.

Joutsensaari, J., Loivamäki, M., Vuorinen, T., Miettinen, P., Nerg, A.-M., Holopainen, J. K., and Laaksonen, A.: Nanoparticle formation by ozonolysis of inducible plant volatiles, Atmos. Chem. Phys., 5, 1489-1495, doi:10.5194/acp-5-1489-2005, 2005.

Kang, E., Root, M. J., Toohey, D. W., and Brune, W. H.: Introducing the concept of Potential Aerosol Mass (PAM), Atmos. Chem. Phys., 7, 5727-5744, doi:10.5194/acp-7-5727-2007, 2007.

Kiendler-Scharr, A., Wildt, J., Dal Maso, M., Hohaus, T., Kleist, E., Mentel, T. F., Tillmann, R., Uerlings, R., Schurr, U., and Wahner, A.: New particle formation in forests inhibited by isoprene emissions, Nature, 461, 381-384, 2009.

Kiendler-Scharr, A., Andres, S., Bachner, M., Behnke, K., Broch, S., Hofzumahaus, A., Holland, F., Kleist, E., Mentel, T. F., Rubach, F., Springer, M., Steitz, B., Tillmann, R., Wahner, A., Schnitzler, J.-P., and Wildt, J.: Isoprene in poplar emissions: effects on new particle formation and $\mathrm{OH}$ concentrations, Atmos. Chem. Phys., 12, 1021-1030, doi:10.5194/acp-12-1021-2012, 2012.

Kuang, C., McMurry, P. H., V., M. A., and Eisele, F.: Dependence of nucleation rates on sulfuric acid vapor concentration in diverse atmospheric locations, J. Geophys. Res.-Atmos., 113, D10209, doi:10.1029/2007JD009253, 2008.

Kulmala, M., Suni, T., Lehtinen, K. E. J., Dal Maso, M., Boy, M., Reissell, A., Rannik, Ü., Aalto, P., Keronen, P., Hakola, H., Bäck, J., Hoffmann, T., Vesala, T., and Hari, P.: A new feedback mechanism linking forests, aerosols, and climate, Atmos. Chem. Phys., 4, 557-562, doi:10.5194/acp-4-557-2004, 2004.

Kulmala, M., Kontkanen, J., Junninen, H., Lehtipalo, K., Manninen, H. E., Nieminen, T., Petäjä, T., Sipilä, M., Schobesberger, S., Rantala, P., Franchin, A., Jokinen, T., Järvinen, E., Äijälä, M., Kangasluoma, J., Hakala, J., Aalto, P. P., Paasonen, P., Mikkilä, J., Vanhanen, J., Aalto, J., Hakola, H., Makkonen, U., Ruuskanen, T., Mauldin, R. L., Duplissy, J., Vehkamäki, H., Bäck, J., Kortelainen, A., Riipinen, I., Kurtén, T., Johnston, M. V., Smith, J. N., Ehn, M., Mentel, T. F., Lehtinen, K. E., Laaksonen, A., Kerminen, V. M., and Worsnop, D. R.: Direct observa- tions of atmospheric aerosol nucleation, Science, 339, 943-946, doi:10.1126/science.1227385, 2013.

Kulmala, M., Nieminen, T., Nikandrova, A., Lehtipalo, K., Manninen, H. E., Kajos, M. K., Kolari, P.and Lauri, A., Petäjä, T., Krejci, R., Hansson, H.-C., Swietlicki, E., Lindroth, A., Christensen, T. R., Arneth, A., Hari, P., Bäck, J., Vesala, T., and Kerminen, V.M.: $\mathrm{CO}_{2}$-induced terrestrial climate feedback mechanism: From carbon sink to aerosol source and back., Boreal Env. Res., 19, 122-131, 2014.

Lehtinen, K., Korhonen, H., Dal Maso, M., and Kulmala, M.: On the concept of condensation sink diameter, Boreal Env. Res., 8, 405-411, 2003.

Leppä, J., Anttila, T., Kerminen, V.-M., Kulmala, M., and Lehtinen, K. E. J.: Atmospheric new particle formation: real and apparent growth of neutral and charged particles, Atmos. Chem. Phys., 11, 4939-4955, doi:10.5194/acp-11-4939-2011, 2011.

Mauldin, R., Frost, G., Chen, G., Tanner, D., Prevot, A., Davis, D., and Eisele, F.: $\mathrm{OH}$ measurements during the First Aerosol Characterization Experiment (ACE 1): Observations and model comparisons, J. Geophys. Res.-Atmos., 103, 16713-16729, 1998.

Mentel, Th. F., Wildt, J., Kiendler-Scharr, A., Kleist, E., Tillmann, R., Dal Maso, M., Fisseha, R., Hohaus, Th., Spahn, H., Uerlings, R., Wegener, R., Griffiths, P. T., Dinar, E., Rudich, Y., and Wahner, A.: Photochemical production of aerosols from real plant emissions, Atmos. Chem. Phys., 9, 4387-4406, doi:10.5194/acp9-4387-2009, 2009.

Mentel, Th. F., Kleist, E., Andres, S., Dal Maso, M., Hohaus, T., Kiendler-Scharr, A., Rudich, Y., Springer, M., Tillmann, R., Uerlings, R., Wahner, A., and Wildt, J.: Secondary aerosol formation from stress-induced biogenic emissions and possible climate feedbacks, Atmos. Chem. Phys., 13, 8755-8770, doi:10.5194/acp-13-8755-2013, 2013.

Merikanto, J., Spracklen, D. V., Pringle, K. J., and Carslaw, K. S.: Effects of boundary layer particle formation on cloud droplet number and changes in cloud albedo from 1850 to 2000, Atmos. Chem. Phys., 10, 695-705, doi:10.5194/acp-10-695-2010, 2010.

Metzger, A., Verheggen, B., Dommen, J., Duplissy, J., Prevot, A. S. H., Weingartner, E., Riipinen, I., Kulmala, M., Spracklen, D. V., Carslaw, K. S., and Baltensperger, U.: Evidence for the role of organics in aerosol particle formation under atmospheric conditions, P. Natl. Acad. Sci. USA, 107, 6646-6651, 2010.

Murphy, S. M., Sorooshian, A., Kroll, J. H., Ng, N. L., Chhabra, P., Tong, C., Surratt, J. D., Knipping, E., Flagan, R. C., and Seinfeld, J. H.: Secondary aerosol formation from atmospheric reactions of aliphatic amines, Atmos. Chem. Phys., 7, 2313-2337, doi:10.5194/acp-7-2313-2007, 2007.

Nieminen, T., Lehtinen, K. E. J., and Kulmala, M.: Sub-10 nm particle growth by vapor condensation - effects of vapor molecule size and particle thermal speed, Atmos. Chem. Phys., 10, 9773 9779, doi:10.5194/acp-10-9773-2010, 2010.

O’Dowd, C. D., Aalto, P. P., Hämeri, K., Kulmala, M., and Hoffmann, T.: Aerosol formation: Atmospheric particles from organic vapours, Nature, 416, 497-498, 2002.

Paasonen, P., Nieminen, T., Asmi, E., Manninen, H. E., Petäjä, T., Plass-Dülmer, C., Flentje, H., Birmili, W., Wiedensohler, A. Hõrrak, U., Metzger, A., Hamed, A., Laaksonen, A., Facchini, M. C., Kerminen, V.-M., and Kulmala, M.: On the roles of sulphuric acid and low-volatility organic vapours in the initial steps 
of atmospheric new particle formation, Atmos. Chem. Phys., 10, 11223-11242, doi:10.5194/acp-10-11223-2010, 2010.

Petäjä, T., Mauldin, III, R. L., Kosciuch, E., McGrath, J., Nieminen, T., Paasonen, P., Boy, M., Adamov, A., Kotiaho, T., and Kulmala, M.: Sulfuric acid and $\mathrm{OH}$ concentrations in a boreal forest site, Atmos. Chem. Phys., 9, 7435-7448, doi:10.5194/acp9-7435-2009, 2009.

Riccobono, F., Schobesberger, S., Scott, C. E., Dommen, J., Ortega, I. K., Rondo, L., Almeida, J., Amorim, A., Bianchi, F., Breitenlechner, M., David, A., Downard, A., Dunne, E. M., Duplissy, J., Ehrhart, S., Flagan, R. C., Franchin, A., Hansel, A., Junninen, H., Kajos, M., Keskinen, H., Kupc, A., Kürten, A., Kvashin, A. N., Laaksonen, A., Lehtipalo, K., Makhmutov, V., Mathot, S., Nieminen, T., Onnela, A., Petäjä, T., Praplan, A. P., Santos, F. D., Schallhart, S., Seinfeld, J. H., Sipilä, M., Spracklen, D. V., Stozhkov, Y., Stratmann, F., Tomé, A., Tsagkogeorgas, G., Vaattovaara, P., Viisanen, Y., Vrtala, A., Wagner, P. E., Weingartner, E., Wex, H., Wimmer, D., Carslaw, K. S., Curtius, J., Donahue, N. M., Kirkby, J., Kulmala, M., Worsnop, D. R., and Baltensperger, U.: Oxidation Products of Biogenic Emissions Contribute to Nucleation of Atmospheric Particles, Science, 344, 717-721, doi:10.1126/science.1243527, 2014.

Roldin, P., Liao, L., Mogensen, D., Dal Maso, M., Rusanen, A., Kerminen, V.-M., Mentel, T. F., Wildt, J., Kleist, E., Kiendler-Scharr, A., Tillmann, R., Ehn, M., Kulmala, M., and Boy, M.: Modelling the contribution of biogenic volatile organic compounds to new particle formation in the Jülich plant atmosphere chamber, Atmos. Chem. Phys., 15, 10777-10798, doi:10.5194/acp-1510777-2015, 2015.

Schobesberger, S., Junninen, H., Bianchi, F., Lönn, G., Ehn, M., Lehtipalo, K., Dommen, J., Ehrhart, S., Ortega, I. K., Franchin, A., Nieminen, T., Riccobono, F., Hutterli, M., Duplissy, J., Almeida, J., Amorim, A., Breitenlechner, M., Downard, A. J., Dunne, E. M., Flagan, R. C., Kajos, M., Keskinen, H., Kirkby, J., Kupc, A., Kürten, A., Kurtén, T., Laaksonen, A., Mathot, S., Onnela, A., Praplan, A. P., Rondo, L., Santos, F. D., Schallhart, S., Schnitzhofer, R., Sipilä, M., Tomé, A., Tsagkogeorgas, G., Vehkamäki, H., Wimmer, D., Baltensperger, U., Carslaw, K. S., Curtius, J., Hansel, A., Petäjä, T., Kulmala, M., Donahue, N. M., and Worsnop, D. R.: Molecular understanding of atmospheric particle formation from sulfuric acid and large oxidized organic molecules, P. Natl. Acad. Sci. USA, 110, 17223-17228, 2013.
Sipila, M., Berndt, T., Petaja, T., Brus, D., Vanhanen, J., Stratmann, F., Patokoski, J., Mauldin, L. R. I., Hyvarinen, A.-P., Lihavainen, H., and Kulmala, M.: The Role of Sulfuric Acid in Atmospheric Nucleation, Science, 327, 1243-1246, 2010.

Smith, J. N., Barsanti, K. C., Friedli, H. R., Ehn, M., Kulmala, M., Collins, D. R., Scheckman, J. H., Williams, B. J., and McMurry, P. H.: Observations of aminium salts in atmospheric nanoparticles and possible climatic implications, P. Natl. Acad. Sci. USA, 107, 6634-6639, 2010.

Spanke, J., Rannik, U., Forkel, R., Nigge, W., and Hoffmann, T.: Emission fluxes and atmospheric degradation of monoterpenes above a boreal forest: field measurements and modelling, Tellus B, 53, 406-422, 2001.

Vanhanen, J., Mikkila, J., Lehtipalo, K., Sipila, M., Manninen, H. E., Siivola, E., Petaja, T., and Kulmala, M.: Particle Size Magnifier for Nano-CN Detection, Aerosol Sci. Tech., 45, 533-542, 2011.

Verheggen, B. and Mozurkewich, M.: An inverse modeling procedure to determine particle growth and nucleation rates from measured aerosol size distributions, Atmos. Chem. Phys., 6, 29272942, doi:10.5194/acp-6-2927-2006, 2006.

Weber, R. J., Marti, J. J., McMurry, P. H., Eisele, F. L., Tanner, D. J., and Jefferson, A.: Measured atmospheric new particle formation rates: Implications for nucleation mechanisms, Chem. Eng. Commun., 151, 53-64, 1996.

Wildt, J., Mentel, T. F., Kiendler-Scharr, A., Hoffmann, T., Andres, S., Ehn, M., Kleist, E., Müsgen, P., Rohrer, F., Rudich, Y., Springer, M., Tillmann, R., and Wahner, A.: Suppression of new particle formation from monoterpene oxidation by $\mathrm{NO}_{\mathrm{x}}$, Atmos. Chem. Phys., 14, 2789-2804, doi:10.5194/acp-14-27892014, 2014.

Zhang, R. Y., Suh, I., Zhao, J., Zhang, D., Fortner, E. C., Tie, X. X., Molina, L. T., and Molina, M. J.: Atmospheric new particle formation enhanced by organic acids, Science, 304, 1487-1490, 2004. 